\title{
Equilibrium Asset Pricing with Leverage and Default
}

Joao F. Gomes

University of Pennsylvania

Follow this and additional works at: https://repository.upenn.edu/fnce_papers

Part of the Finance and Financial Management Commons

\section{Recommended Citation}

Gomes, J. F. (2016). Equilibrium Asset Pricing with Leverage and Default. The Wharton School Research Paper, (92), Retrieved from https://repository.upenn.edu/fnce_papers/29 


\title{
Equilibrium Asset Pricing with Leverage and Default
}

\author{
Abstract \\ We develop a general equilibrium model linking the pricing of stocks and corporate bonds to endogenous \\ movements in corporate leverage and aggregate volatility. The model has heterogeneous firms making \\ optimal investment and financing decisions and connects fluctuations in macroeconomic quantities and \\ asset prices to movements in the cross-section of firms. Empirically plausible movements in leverage \\ produce realistic asset return dynamics. Countercyclical leverage drives predictable variation in risk \\ premia, and debt-financed growth generates a high value premium. Endogenous default produces \\ countercyclical aggregate volatility and credit spread movements that are propagated to the real \\ economy through their effects on investment and output. \\ Disciplines \\ Finance and Financial Management
}




\title{
Equilibrium Asset Pricing with Leverage and Default*
}

\author{
João F. Gomes ${ }^{\dagger} \quad$ Lukas Schmid ${ }^{\ddagger}$
}

March 2016

\begin{abstract}
We develop a general equilibrium model linking the pricing of stocks and corporate bonds to endogenous movements in corporate leverage and aggregate volatility. The model has heterogeneous firms making optimal investment and financing decisions and connects fluctuations in macroeconomic quantities and asset prices to movements in the cross-section of firms. Empirically plausible movements in leverage produce realistic asset return dynamics. Countercyclical leverage drives predictable variation in risk premia, and debt-financed growth generates a high value premium. Endogenous default produces countercyclical aggregate volatility and credit spread movements that are propagated to the real economy through their effects on investment and output.
\end{abstract}

\footnotetext{
*This paper replaces a previous version entitled "Equilibrium Credit Spreads". We are grateful to comments from Andy Abel, Hui Chen, Urban Jermann, Aubhik Kahn, Dmitry Livdan, Neng Wang and participants at seminars in Calgary, Carnegie-Mellon, Duke, Wharton, NY Fed, NYU, Richmond Fed, ECB, UBC, UCLA, and Imperial College, as well as the following conferences: AFA, SED, Minnesota Macro Week, NBER Capital Markets, NYU Five Star, Rimini Macro-Finance, UCSB-LAEF, Venice C.R.E.D.I.T, and ESSFM Gerzensee. All errors remain our own.

${ }^{\dagger}$ The Wharton School, University of Pennsylvania. Email: gomesj@wharton.upenn.edu

${ }^{\ddagger}$ The Fuqua School of Business, Duke University. Email: lukas.schmid@duke.edu
} 


\section{Introduction}

It is now well understood that leverage is a major driver of risk exposure and a key contributor to macroeconomic fluctuations. Leverage pushes many corporations to default in downturns often with substantial losses. In turn, expectations of those losses affect the pricing of corporate debt whose issuance aids successful financing of growth options and helps accelerating expansions. Debtfinanced booms and debt-driven busts then contribute to aggregate volatility, and are reflected in asset returns, as the Great Recession of 2008-09 has reminded us. In spite of this, developing a framework suitable to study the joint determination of corporate investment and leverage decisions of firms, macroeconomic fluctuations, and risk premia on stocks and corporate bonds has proved challenging.

This paper is an attempt to fill this gap. It presents a general equilibrium model with heterogeneous firms making optimal investment and financing decisions under uncertainty, and brings together many core insights from asset pricing, capital structure, and macroeconomics. Our model reconciles, in a unified framework, several core stylized facts about asset returns while also addressing many key features in macroeconomic aggregate and firm-level investment and financing variables. Specifically, we show that our model produces a sizable average equity premium and credit spread, together with plausibly low average returns on safe assets. In the time series the model also implies that both price-dividend ratios and credit spreads have substantial predictive power for future stock returns, while the cross-section of stock returns delivers a significant value premium.

In the model, quantitatively realistic asset return dynamics are driven by empirically plausible, endogenous movements in leverage, both in time series and cross-section. In fact, a major contribution of our model is that it delivers an explicit connection between fluctuations in the cross-sectional distribution of firms and the time-series movements in macroeconomic aggregates and financial prices. Indeed, this link is critical, as the mass of firms close to default, and hence the credit spread, becomes a key determinant of aggregate volatility and asset prices.

Endogenous movements in leverage contribute to the amplification and propagation of aggregate consumption risks and volatility. Debt-financed booms and busts amplify aggregate volatility, while 
accounting for a realistic long-term maturity structure of corporate debt significantly increases the persistence of fluctuations. This amplification raises the volatility of the market price of risk and produces quantitatively realistic risk premia. Importantly, endogenous default also increases the volatility of consumption during recessions, as the mass of firms burdened by excessive leverage and closer to default grows. As a consequence, the equilibrium market price of risk also becomes sharply countercyclical.

Endogenous movements in leverage also explain much of our findings about predictability in both time-series and cross-section. Countercyclical leverage drives up risk premia on financial assets in downturns which, in the time series, is naturally reflected in both price-dividend ratios and credit spreads. Cross-sectionally, because investment is, at least partially, debt financed, value firms tend to have higher leverage ratios and these cross-sectional differences in leverage between growth and value firms amplify the dispersion in equity risk, and are a major driver of the value premium.

Some of these mechanisms are also shared by several partial equilibrium models of equity returns, even if leverage is exogenous and there are no financing frictions. ${ }^{1}$ In such models however, leverage affects assets' conditional betas only through a direct cash flow effect which is often magnified by correlated, but exogenous, movements in discount rates. By contrast, in our general equilibrium setting, the main impact of leverage is felt indirectly though its general equilibrium impact on the stochastic discount factor. This is because movements in leverage are endogenously linked to the dynamics of aggregate consumption. To be sure, in our model, both cash flow and discount rate effects are important and interact with each other. Nevertheless, it is the general equilibrium movements in consumption dynamics and the stochastic discount rate effect that arise as quantitatively more important determinants of asset return dynamics.

Because defaults tend to cluster in downturns, when the market price of risk is high, credit spreads contain a significant and volatile credit risk premium compensating consumers for losses in bad states. Accordingly, credit spreads exhibit significant time-series variation that spills over into the real economy. In expansions, default risk and the market price of risk are low, so that debtfinanced investment is cheap, while credit spreads spike up in recessions, due to rises in default

\footnotetext{
${ }^{1}$ Carlson, Fisher and Giammarino (2004), Zhang (2005), Livdan, Sapriza, and Zhang (2009), Gomes and Schmid (2010), Ozdagli (2012), Obreja (2013), Kuehn and Schmid (2014).
} 
rates and the credit risk premium. These endogenous movements in credit prices contribute to amplify the effects of shocks and generate more pronounced business cycle fluctuations. Much like in the data, credit spreads predict business cycles, providing an effective early warning for impending recessions. This is because the risk premium is very informative about the tail of the cross-sectional firm distribution beyond aggregate productivity. ${ }^{2}$

A growing body of work has started to provide an integrated discussion of asset prices, leverage, and aggregate cycles in a modern setting, but our emphasis on risk premia is fairly unique. Existing general equilibrium macro models that explain the cyclical behavior of credit markets and their correlation with macroeconomic aggregates largely abstract from variations in risk premia and asset prices. ${ }^{3}$ Unlike these classic financial accelerator papers, movements in credit spreads in our paper are mostly due to variations in credit risk premia and do not require large spikes in observed default events. In fact, in our model changes in risk premia drive about two thirds of the credit spread and also account for most of its predictive power.

A parallel literature has sought to link credit risk to the financing decisions of firms and, more recently, to exogenous movements in risk premia and aggregate factors. ${ }^{4}$ Relative to that line of work, we show how embedding a detailed model of credit risk into general equilibrium has important implications for endogenous volatility and risk pricing. ${ }^{5}$ Closer to our work is Favilukis, Lin, Zhou (2015) who also use a production and investment model with heterogeneous firms to address the impact wage rigidities on the determination of credit spreads. They mostly abstract from other issues such as the patterns in investment and leverage data and the links between credit and equity markets that we emphasize here. Conversely, Begenau and Salomao (2015) study a partial equilibrium model with heterogenous firms that offers a much more detailed analysis of

\footnotetext{
${ }^{2}$ Examples of the ability of credit spreads to forecast economic activity include studies by Keim and Stambaugh (1986), Schwert (1989), Stock and Watson (1991), Fama and French (1992), Lettau and Ludvigson (2004), Gilchrist and Zakrajsek (2008), and Mueller (2008).

${ }^{3}$ Classic examples include Kyotaki and Moore (1997) and Bernanke, Gertler, and Gilchrist (1999). More recent contributions are Jermann and Quadrini (2010) and Khan and Thomas (2012).

${ }^{4}$ Building on Leland (1994) recent quantitatively successful contributions include Hackbarth, Miao, and Morellec (2006), Sundaresan and Wang (2010), Chen, Collin Dufresne, and Goldstein (2008), Bhamra, Kuhn, and Strebualev (2010), and Chen (2010). More recently, some papers such as Ai, Kiku, and Li (2013) and Mitra (2014) have developed quantitative models of firm financing based on dynamic contracting in risk-sensitive environments.

${ }^{5}$ Miao and Wang (2010) extend our framework to allow for endogenous labor supply, while Gourio (2010) introduces disaster risk in a setting where firms live for two periods to ensure there is no role for firm heterogeneity in equilibrium.
} 
cross-sectional differences in firm financing patterns over the business cycle, while mostly ignoring asset pricing data.

There is also a number of general equilibrium models with production and investment that exploits the role of asset prices and risk premia explicitly. However they all generally ignore the role of credit markets and credit risk. ${ }^{6}$ Relative to these papers, our main contribution is to offer a more detailed general equilibrium model with production and financing and explicitly link the movements in asset prices to endogenous changes in macroeconomic quantities. In this respect, our work is related to general equilibrium models that incorporate firm heterogeneity in order to address cross-sectional patterns in stock returns such as the value premium. ${ }^{7}$ In contrast to these contributions, in our model with endogenous financing, leverage emerges as an important determinant of the cross-section of returns.

The rest of the paper is organized as follows. Section 2 describes our general equilibrium model and some of its properties, while Section 3 discusses some of the issues associated with solving it numerically. A detailed discussion of our findings is provided in Section 4, before we conclude.

\section{The Model}

In this section we describe a general equilibrium model with heterogeneous firms that are financed with both debt and equity. The model is designed to merge many key features of the investment and financing behavior of firms in a modern asset pricing setting.

Firms produce a unique final good that can be used for both consumption and investment. They own, and can add to, their capital stock by taking advantage of stochastic investment opportunities. Debt is used because of its tax benefits and because equity issues are costly. Hence the capital structure reflects and combines the key elements of both modern trade off and pecking order theories. Both debt and equity can be issued regularly although there are issuance costs. Excessive debt may cause some firms to default. On the other hand, attractive business and credit conditions

\footnotetext{
${ }^{6}$ Some examples are Jermann (1998), Tallarini (2000), Lochstoer and Kaltenbrunner (2010), Ai, Croce, Li (2010), Croce (2014), and Kung and Schmid (2015).

${ }^{7}$ Examples along these lines include Gomes, Kogan, and Zhang (2003), Gala (2010) Garleanu, Panageas, and Yu (2010), and Papanikolaou (2010)
} 
may also encourage new entrants to join in production.

\section{$2.1 \quad$ Firms}

The production sector of the economy is made of a continuum of firms that differ in their productivity, size, and leverage, among other characteristics. In describing the problem of firms we take the stochastic discount factor for the economy as given. We show later how this is determined in general equilibrium by the optimal consumption and savings decisions of households. Nevertheless, it is important to recognize from the outset that firms' discount rates depend on the aggregate state of the economy, denoted $s$. As we will show, this includes both the current state of the aggregate shocks and the equilibrium cross-sectional distribution of firms.

\subsubsection{Technology}

All firms produce the same homogeneous final good that can be used for consumption or investment. The production function denoting the instantaneous flow of output is described by the expression:

$$
y_{j t}=\exp \left(x_{t}+z_{j t}\right) k_{j t}
$$

where $k_{j t}$ denotes the firm's productive capacity and $x_{t}$ and $z_{j t}$ denote the values of aggregate and firm specific productivity, respectively. The behavior of these follows a first order autoregressive process with normal innovations:

$$
\begin{aligned}
x_{t} & =\left(1-\rho_{x}\right) \bar{x}+\rho_{x} x_{t-1}+\sigma_{x} v_{x t} \\
z_{j t} & =\rho_{z} z_{j, t-1}+\sigma_{z} v_{z j t}
\end{aligned}
$$

where $v_{x t}$ and $v_{z j t}$ are independently and identically distributed shocks drawn from standard normal distributions. We use $N\left(x_{t+1} \mid x_{t}\right)$ and $N\left(z_{t+1} \mid z_{t}\right)$ to denote the conditional cumulative c.d.f of these two variables.

A growing literature has emphasized the importance of non-normal or disaster shocks and time variation in volatility (e.g. Bloom (2009), Gourio (2010), Gilchrist et al (2011)). We choose not to 
include them to illustrate better how a detailed general equilibrium production model can generate endogenously the stochastic consumption volatility that is a key feature of several popular asset pricing models with exogenous consumption (e.g Drechsler and Yaron (2010)).

\subsubsection{Investment Opportunities}

Each period firms have the opportunity to increase next period's stock of capital $k_{j t+1}$. Investment takes place by adopting a new project of discrete size. Each adopted project costs $i$ goods per unit of capital, and it scales the stock of capital to $k_{j t+1}=g \times k_{j t}$. In other words, to increase next period's stock of capital by a constant (net) factor of $g-1$ the firm must surrender $i \times k_{j t}$ units of current cash flow. ${ }^{8}$

Assuming the cumulative distribution of investment costs, denoted $H(i)$, is uniform and independent over time with $\mathrm{E} i=g-1$, we can write the law of motion for a typical firm's stock of capital as:

$$
k_{j t+1}=\left\{\begin{array}{lll}
k_{j t} & \text { with prob. } & 1-H\left(\bar{i}_{t}\right) \\
g k_{j t} & \text { with prob. } & H\left(\bar{i}_{t}\right)
\end{array}\right.
$$

Thus, only firms drawing a sufficiently low cost of adopting a new project will choose to increase their productive capacity. We discuss the determination of the cutoff investment cost, $\bar{i}_{t}$, below. Hence our model will produce an endogenous cross-sectional variation in firm size over time as firms optimally take advantage of differing investment opportunities. Finally, we assume maintenance of the existing capital stock entails periodic costs, $\delta k_{j t}$, akin to depreciation.

\subsubsection{Firm Earnings and Financing}

Firms can finance part of their spending through debt. We assume that this takes the form of a callable consol bond that pays a fixed coupon $\tilde{b}_{j t}$ as long as the debt is not called or the firm does not default on its obligations.

\footnotetext{
${ }^{8}$ The usual assumption is of course that $i=g-1$ at all times. Here we generalize it to allow for the investment cost to be stochastic and differ across firms.
} 
New debt can be issued in every period. To avoid dealing with multiple state variables at the same time however we assume that all existing debt is recalled at the same time. Without loss of generality we assume that debt is always recalled at market value, denoted $B(k, \tilde{b}, z, s)$. In words, this is the current value of a callable, defaultable, claim on a firm of size $k_{j t}$ with current idiosyncratic productivity $z_{j t}$, that promises to pay $\tilde{b}$ per period, at a time when the aggregate state of the economy is given by $s_{t}$.

It follows that, except for gross investment expenditures, the after-tax cash flows to the firm's equity holders, $\Pi(\cdot)$ are given by:

$$
\Pi\left(k, \tilde{b}, \tilde{b}^{\prime}, z, s\right)=(1-\tau)(\exp (x+z)-\delta) k-\tilde{b}+\left(1+\chi_{b} \kappa_{b}\right) B\left(k, \tilde{b}^{\prime}, z, s\right)-B(k, \tilde{b}, z, s)
$$

where we now drop subscripts and use the notation $\tilde{b}^{\prime}=\tilde{b}_{j, t+1}$ and the indicator function $\chi_{b}$ takes the value of 1 when the firm changes its debt decision, i.e. $\tilde{b}^{\prime} \neq \tilde{b}$. The variable $\kappa_{b} \geq 0$ captures transaction costs, such as underwriting fees, associated with calling and reissuing debt, while $\tau$ denotes the effective tax rate on profits adjusted for taxes on distributions and personal interest income. Finally, we assume firms can also fund themselves with new equity issues. Equity issues too are costly and we use $\kappa_{e} \geq 0$ to capture the unit costs associated with issuing any new equity.

\subsubsection{Default and Debt Pricing}

As discussed above, bondholders receive a periodic coupon payment as long as the firm does not default or debt is recalled. If debt is called they pocket the current market value of the debt, $B(k, \tilde{b}, z, s)$. The only scenario under which they experience losses is upon default. Limited liability ensures that it is optimal for equity holders to default on their debt obligations whenever the equity value, denoted $V(k, \tilde{b}, z, s)$, becomes negative. Mathematically, this yields a default cutoff value for the idiosyncratic shock, $\bar{z}(k, \tilde{b}, x)$, that is defined implicitly by:

$$
V(k, \tilde{b}, \bar{z}(k, \tilde{b}, s), s)=0
$$

We show in the appendix that $\bar{z}$ is increasing in leverage, $\tilde{b} / k$. 
If default occurs we assume that the firm's assets (its capital plus current cash flows) are liquidated and the proceeds used to pay its creditors. A fraction $\phi>0$ of these assets however is lost in liquidation so that creditors recover an amount equal to $(1-\phi)(1-\delta+x z) k$. Given these possibilities, the market value, $B\left(k, \tilde{b}^{\prime}, z, s\right)$, of a claim promising to pay $\tilde{b}^{\prime}$ tomorrow, in a firm currently in state $(k, b, z, s)$, obeys the recursion:

$$
\begin{aligned}
B\left(k, \tilde{b}^{\prime}, z, s\right) & =\mathrm{E}_{\mathrm{s}} M\left(s, s^{\prime}\right)\left[\int_{\bar{z}\left(k^{\prime}, \tilde{b}^{\prime}, s^{\prime}\right)}\left[\tilde{b}^{\prime}+B\left(k^{\prime}, \tilde{b}^{\prime}, z^{\prime}, s^{\prime}\right)\right] d N\left(z^{\prime} \mid z\right)\right. \\
& \left.+\int^{\bar{z}\left(k^{\prime}, \tilde{b}^{\prime}, s^{\prime}\right)}(1-\phi)\left(1-\delta+\exp \left(x^{\prime}+z^{\prime}\right)\right) k^{\prime} d N\left(z^{\prime} \mid z\right)\right]
\end{aligned}
$$

where we take households/investors stochastic discount factor, $M\left(s, s^{\prime}\right)$, as given for the moment. Some basic properties of the market value of debt are established in the appendix.

Linearity of technology, investment and default costs in $k$ implies that both equity and bond values are also linear in firm size, $k$, and that the only endogenous state variable is the leverage ratio, $b=\tilde{b} / k$. It follows that the default threshold obeys $\bar{z}(k, \tilde{b}, s)=\bar{z}(b, s)$.

Henceforth, we will simplify the notation and generally work with the normalized equity value function $P(b, z, s)=V(k, \tilde{b}, z, s) / k$. Similarly, we will use $Q(b, z, s)=B(k, \tilde{b}, z, s) / k$ to denote the normalized market value of debt.

Equation (7) shows how changes in the recovery rate, $\phi$, directly affect the relative price of credit to the firm. Thus changes in $\phi$ act as effective shocks to credit supply, leading to tighter credit conditions and increases in credit spreads. ${ }^{9}$ To study the effect of financial shocks we also consider an expanded version of our model where we let $\Gamma\left(\phi^{\prime} \mid \phi\right)$ denote the conditional distribution of expected recovery rates $\phi$.

\footnotetext{
${ }^{9}$ Eisfeldt and Rampini (2007) show these types of "liquidity" shocks can be important to explain measured variation in individual firm investment over time, while Jermann and Quadrini (2011) and Khan and Thomas (2013) show how they can important to explain macroeconomic fluctuations.
} 


\subsubsection{Equity Value and Optimal Investment}

We can now characterize the decisions of equity holders in detail. At every point in time the equity value (per unit of capital) obeys:

$$
P(b, z, s)=\max \left\{P^{0}(b, z, s), P^{I}(b, z, s)\right\}
$$

where $P^{I}(b, z, s)$ denotes the equity value of a firm after it adjusts its stock of capital and $P^{0}(b, z, s)$ denotes that of a firm that chooses not to invest at all. The inaction value, $P^{0}(\cdot)$ is determined recursively by the Bellman equation:

$$
P^{0}(b, z, s)=\max \left\{0, \max _{b^{\prime}}\left\{\left(1+\chi_{e} \kappa_{e}\right) \pi\left(b, b^{\prime}, z, s\right)+\mathrm{E}_{\mathrm{s}} M\left(s, s^{\prime}\right) \int_{\bar{z}\left(b^{\prime}, s^{\prime}\right)} P\left(b^{\prime}, z^{\prime}, s^{\prime}\right) N\left(d z^{\prime} \mid z\right)\right\}\right\}
$$

Here $\pi(\cdot)=\Pi(\cdot) / k$ and $\chi_{e}$ is an indicator function that takes the value of 1 when the firm raises

new equity and pays issuance costs $\kappa_{e} \geq 0$. The truncation in the continuation value reflects the impact of the possibility of default on the returns to equity holders. In turn the value of investing, $P^{I}(\cdot)$ obeys:

$P^{I}(b, z, s)=\max \left\{0, \max _{b^{\prime}}\left\{\left(1+\chi_{e} \kappa_{e}\right)\left[\pi\left(b, b^{\prime}, z, s\right)-i\right]+g \cdot \mathrm{E}_{\mathrm{s}} M\left(s, s^{\prime}\right) \int_{\bar{z}\left(b^{\prime}, s^{\prime}\right)} P\left(b^{\prime}, z^{\prime}, s^{\prime}\right) N\left(d z^{\prime} \mid z\right)\right\}\right\}$

Setting $P^{I}(b, z, s)=P^{0}(b, z, s)$ yields an optimal investment cutoff:

$$
\bar{i}(b, z, s)=(g-1)\left[\max _{b^{\prime}}\left\{\frac{\mathrm{E}_{\mathrm{s}} M^{\prime} \int_{\bar{z}^{\prime}} P\left(b^{\prime}, z^{\prime}, s^{\prime}\right) d z}{1+\chi_{e} \kappa_{e}}+Q\left(b^{\prime}, z, s\right)\right\}\right]
$$

When equity issuance costs, i.e. $\kappa_{e}=0$, the term in square brackets is exactly Tobin's average $q$. It equals the expected value of all equity and debt claims on the firm, normalized by the value of the current stock of capital. In this case the optimal investment rule implies that a firm will invest if and only if Tobin's $q$ exceeds $i /(g-1)$. For the marginal firm this is exactly 1 , so that, at the aggregate level, this economy behaves very much like one with an aggregate investment technology exhibiting convex adjustment costs. 
This concludes our description of the individual firm decisions. The appendix establishes a number of key properties about the relevant value and policy functions and Figures 1 and 2 illustrate them using the benchmark parameter values discussed below. Most of these properties are fairly intuitive. But it is worth noting that the investment cutoff $\bar{i}(\cdot)$ is declining in the existing coupon payment $b$, which means high leverage firms are less likely to invest - a "debt overhang" result.

Also important is the fact that if the discount factor $M(\cdot)$ is constant the default cut-off $\bar{z}(b, s)$ becomes linear in $x$. In this case changes to aggregate productivity produce symmetric responses in the the default cutoff and default rates over the business cycle. ${ }^{10}$ By contrast allowing for a significant role for risk premia, ties $M(\cdot)$ to $x$ and leads to asymmetric responses to aggregate shocks.

\subsection{Aggregation}

To characterize the general equilibrium of the model we must aggregate the optimal policies of each individual firm to construct macroeconomic quantities for our economy.

\subsubsection{Cross-Sectional Distribution of Firm}

We begin by defining $\mu_{t}=\mu(s)=\mu(b, z, x, \phi)$ as the cross-sectional distribution of firms over leverage, $b$, and idiosyncratic productivity, $z$, at the beginning of period $t$, when the state of aggregate productivity is $x$ and the recovery rate on assets in default $\phi$.

Our timing is chosen so that that $\mu(\cdot)$ is constructed before any current period decisions take place. As is well known, this cross-sectional distribution will move over time in response to the aggregate state of the economy and will be the main computational obstacle to solving the model.

Given this distribution it is straightforward to define the total mass of firms at the beginning of the current period as:

$$
F(s)=F_{t}=\int d \mu_{t}
$$

Like $\mu(s)$ itself, $F(s)$ is constructed before individual firms' decisions are made.

\footnotetext{
${ }^{10}$ Popular examples are Bernanke et al (1997), Gertler and Karadi (2010).
} 
Similarly, we can construct the equilibrium default rate in the economy as:

$$
D(s)=1-\frac{\int_{z \geq \bar{z}(b, s)} d \mu}{F(s)}
$$

Since the default threshold, $\bar{z}(b, s)$, is decreasing in $x$ this default rate will be countercyclical and, as discussed above, will generally respond asymmetrically to positive and negative shocks in $x$.

\subsubsection{Firm Entry}

Entry is necessary in the model to replace bankrupt firms and ensure a stationary distribution of firms in equilibrium. Accordingly, we assume that every period a mass of potential new entrants arrives in the economy. Potential entrants behave similarly to incumbents but face different initial conditions. Specifically, potential new entrants:

- have no initial level of debt, so that $b_{j t}=0$

- draw an initial realization of the idiosyncratic shock, $z_{j t+1}$, from the long-run invariant distribution implied by $(3)$, denoted $N^{\star}(z)$;

We assume entrants start with no capital and make an initial investment of size $\alpha \bar{k}_{t}$, where:

$$
\bar{k}_{t}=\frac{\int k_{j t} d \mu_{t}}{F_{t}}
$$

denotes average firm size at time $t$. We will assume new firms start small so that $\alpha<1$.

Like incumbents, entrants differ in the cost of this initial investment. For the sake of symmetry and parsimony we assume that the unit cost of their investment opportunities, $e$, is also drawn from the c.d.f. $H(e)$. As with incumbents, this implies that only firms drawing costs below the cutoff, $\bar{e}(z, s)$, find it optimal to invest and thus enter the market. 


\subsubsection{Aggregate Investment}

Given the optimal behavior of individual firms, gross aggregate investment is equal to:

$$
I(s)=\int_{0}^{\bar{i}(s)} i k d H(i)+\int_{0}^{\bar{e}(s)} e \bar{k} d H(e)-\int(1-\chi) k d \mu+\int \delta k d \mu
$$

The first two terms sum the total investment costs of newly adopted projects, incurred by existing firms and by new entrants respectively. We then net out the disinvestment proceeds associated with asset liquidation by defaulting firms. The last term adds the depreciation expenditures of all incumbent firms.

Since investment and default decisions are independent of $k$ the law of large numbers implies that aggregate investment is given by:

$$
I(s)=K(s)\left[\int_{0}^{\bar{i}(s)} i d H(i) / F(s)+\int_{0}^{\bar{e}(s)} e d H(e) / F(s)-D(s)+\delta\right]
$$

where $K(s)=\int k d \mu(s)=\bar{k}(s) F(s)$ is the aggregate capital stock in the economy, when the aggregate state is $s$.

Linearity of the aggregate production technology and investment expenditures ensures that our economy will grow endogenously over time at a stochastic rate that is linked to average aggregate productivity $x_{t}$. Faced with these aggregate shocks, our economy will exhibit persistent variation over time in the growth rates of output and consumption among others, providing a natural laboratory to investigate the effects of shocks to long run growth rates in a general equilibrium context with endogenous quantities and prices. ${ }^{11}$

The expression for aggregate investment (15) integrates, in a parsimonious way, elements of rising marginal adjustment costs and partial irreversibility, both of which are important to generate quantitatively interesting behavior in asset prices. Bacause optimal investment cutoffs are increasing in productivity, the marginal cost of (aggregate) investment rises in good times, much

\footnotetext{
${ }^{11}$ If the arrival of investment projects to new and old firms $H(\cdot)$ is time varying, the model easily accommodates the type of investment specific technological shocks that have been emphasized recently in the literature (e.g.Papanikolaou (2011) and Kogan and Papanikolaou (2013))
} 
like it would in a simple aggregate model with standard convex adjustment costs (e.g. Jermann (1998)). And since bankruptcy is costly, investment becomes in effect only partially reversible, thus adding endogenous counter-cyclical variation to consumption growth in general equilibrium. This endogenously increases the market price of risk during recessions and exacerbates underlying variations in equilibrium asset prices.

\subsubsection{Other Aggregate Quantities}

Other aggregate quantities can be define straightforwardly.. Aggregate output is given by:

$$
Y(s)=\int \exp (x+z) k d \mu
$$

while the losses associated with bankruptcy are given by:

$$
\Phi(s)=\int(1-\chi) \phi(1+\exp (x+z)) k d \mu
$$

Finally we can also construct the aggregate market value of corporate equity and debt respectively with the expressions:

$$
V(s)=\int P(s, z, b) k d \mu
$$

and

$$
B(s)=\int Q(s, z, b) k d \mu
$$

These definitions for the aggregate quantities make it clear that the aggregate state of our

economy $s$ is the triplet $(x, \phi, \mu)$. All aggregate quantities and prices depend on the average state of productivity, financial conditions as well as the cross-sectional variation in firm productivities and leverage.

\subsection{Households}

To close our general equilibrium model we now describe the behavior and constraints faced by the households/investors. We assume that the economy is populated by a competitive representative 
agent household, that derives utility from the consumption flow of the single consumption good, $C_{t}$. This representative household maximizes the discounted value of future utility flows, defined through the Epstein-Zin (1991) and Weil (1990) recursive function:

$$
U_{t}=\left\{(1-\beta) u\left(C_{t}\right)^{1-1 / \sigma}+\beta E_{t}\left[U_{t+1}^{1-\gamma}\right]^{1 / \kappa}\right\}^{1 /(1-1 / \sigma)} .
$$

The parameter $\beta \in(0,1)$ is the household's subjective discount factor and $\gamma>0$ is the coefficient of relative risk aversion. The parameter $\sigma \geq 0$ denotes the elasticity of intertemporal substitution and $\kappa=(1-\gamma) /(1-1 / \sigma)$.

The household invests in shares of each existing firm as well as a riskless bond in zero net supply that earns a period rate of interest $r_{t}$. We also assume that there are no constraints on short sales or borrowing and that households receive the proceeds of corporate income taxes as a lump-sum rebate equal to:

$$
T(s)=\tau \int \exp (x+z) k d \mu
$$

Given these assumptions the equilibrium stochastic discount factor that must be used to compare cash flows across two adjacent periods is defined by the expression:

$$
M_{t, t+1}=\left[\beta\left(\frac{C_{t+1}}{C_{t}}\right)^{-1 / \sigma} R_{W, t+1}^{1-1 / \kappa}\right]^{\kappa} .
$$

where

$$
R_{W, t+1}=\frac{W_{t+1}}{W_{t}-C_{t}}
$$

is the return on total household wealth, including bonds and tax proceeds.

As is well known, the absence of arbitrage implies that all gross asset returns in this economy will satisfy:

$$
\mathrm{E}_{t}\left[M_{t+1} R_{i, t+1}\right]=1
$$

for all assets $i$, including the equity and bond investments in the firms described above. 


\subsection{General Equilibrium}

Optimal investor behavior determines the equilibrium stochastic discount factor, $M\left(s, s^{\prime}\right)$, given household wealth. Earlier we described optimal firm behavior given the stochastic discount factor and showed how it determines aggregate investment and output as well as household wealth. Ensuring consistency between these two pieces of the economy requires that aggregate consumption by households is equal to aggregate production, net of investment and deadweight losses.

Formally our competitive equilibrium can then be constructed by imposing the additional consistency condition:

$$
C_{t}=C(s)=Y(s)-I(s)-\Phi(s)
$$

This ensures that the stochastic discount factor used by each firm corresponds to that implied by optimal household behavior. ${ }^{12}$

Finally we also need to specify a law of motion for the cross-sectional measure of firms over time. Given optimal firm policies this measure satisfies the following relation:

$$
\begin{aligned}
\mu\left(z^{\prime}, b^{\prime}, x^{\prime}, \phi^{\prime}\right) & =\operatorname{Prob}\left(z_{t+1}<z^{\prime}, b_{t+1}<b^{\prime}, x_{t+1}<x^{\prime}, \phi_{t+1}<\phi^{\prime}\right) \\
& =\Gamma\left(\phi^{\prime} \mid \phi\right) N\left(x^{\prime} \mid x\right)\left[\int \chi N\left(z^{\prime} \mid z\right) \Omega_{b(z, b, x, \phi)=b^{\prime}} d \mu(z, b, x, \phi)+N^{\star}\left(z^{\prime}\right) \Omega_{b(0,0, x, \phi)=b^{\prime}}\right]
\end{aligned}
$$

where $\Omega$ is an indicator function that takes the value of 1 if the optimal policy function $b(z, b, x, \phi)$ equals $b^{\prime}$ and 0 otherwise. $N(\cdot), N^{\star}(\cdot)$ and $\Gamma(\cdot)$ are the cumulative distributions defined earlier.

The terms outside brackets in equation (27) capture the exogenous evolution in the aggregate states. The first term inside the brackets sums all the surviving firms which choose optimal leverage $b^{\prime}$ across all current states next period. The second term adds the mass of all entering firms that also choose optimal leverage equal to $b^{\prime}$. Recall that new firms arrive at the current period with $z=b=0$.

Figure 3 shows how the cross-sectional distribution changes after a long sequence of positive or negative shocks to aggregate productivity, $x$. Each panel depicts the equilibrium marginal

\footnotetext{
${ }^{12}$ We follow the convention of considering that bankruptcy costs are deadweight losses but in a general equilibrium model this is a somewhat debatable choice, since some of these costs might be in the form of legal and accounting fees that accrue to other types of firms in the economy.
} 
distribution over debt commitments, $\mu(\cdot, b, \cdot, \cdot)$. This reflects both the effects of truncation by exit, refinancing and investment from incumbent firms, and the lumpy additions from new entrants. In expansions, most firms find it optimal to refinance at higher levels so as to fund the exercise of valuable growth options. Similarly, new entrants will be relatively highly levered, and these two effects combine to thin out the left tail of the distribution. During contractions however, many firms will find themselves burdened with excessive debt and optimally choose to default. At the same time, less attractive growth opportunities lead to fewer issues of new debt and to a larger concentration of low (book) debt firms. Taken together, these effects will reduce the mass of firms at the right tail of the distribution. As we will show later, the predictive power of credit spreads comes from their ability to summarize the tail behavior of the cross-sectional distribution, $\mu(\cdot)$.

\section{Computation and Calibration}

This section offers a brief description of our approach to solve the model in section 2 and the choice of parameter values. As discussed above, the main obstacle to the computation of the competitive equilibrium is the fact that the cross-sectional measure of firms $\mu(\cdot)$ changes over time. In spite of this, and the level of detail in capturing firm behavior, our model remains relatively parsimonious and relies on relatively few independent parameters.

\subsection{Computation}

Computing the competitive equilibrium requires the following three basic steps:

- Given an initial stochastic discount factor $M\left(s, s^{\prime}\right)$ solve the problem of each individual firms and determine the equilibrium level of entry and default

- Aggregate individual firm decisions and use the consistency condition (26) to compute aggregate consumption and wealth

- Ensure that the implied aggregate quantities are consistent with the initial process for $M\left(s, s^{\prime}\right)$.

Convergence of this procedure delivers the equilibrium values for all individual and aggregate quantities in the model. Appendix 6 described this procedure in more detail. 


\subsection{Parameter Choices}

In the benchmark model there are no credit market shocks and the recovery rate, $\phi$, does not move over time. This requires us to specify the value of fourteen parameters: three for preferences, seven for technology, and another four to capture institutional or policy features. Table 1 summarizes our choices.

The preference parameters are $\beta, \gamma$ and $\sigma$. They are chosen to ensure that the model matches the key properties of the risk free rate and the aggregate equity premium in the economy. Several studies have already shown how to combine time non-separable preferences and persistent shocks to aggregate growth to produce these results. More recent papers have expanded this analysis to general equilibrium models with all equity firms. Our parameter values are quite similar to several papers in this literature. ${ }^{13}$

For the technology parameters we set the maintenance cost of capital $\delta$ to $2.1 \%$ per quarter, a value consistent with standard estimates of capital depreciation rates. Our choice of $\alpha$ is set to be consistent with relative size of new entrants, reported by Davis and Haltiwanger (1992). The size of growth options, $g$, is chosen to be consistent with the evidence on the lumpy nature of firm-level investment. In particular, we set it to match the empirical frequency of investment spikes of about 0.06 per quarter (Davis and Haltiwanger (1992)).

The volatility and persistence of the aggregate productivity process are set to $\rho_{x}=0.96$ and $\sigma_{x}=0.012$, largely in line with other macro studies and ensuring that we match the volatility and persistence of output growth in the data. The parameters for idiosyncratic shocks can be chosen to match a number of different moments of the cross-sectional distribution of firms. Since we are especially concerned with the role of default rates and credit spreads in our economy we set these parameters to match the unconditional means of both of these variables. This implies that $\rho_{z}=0.92$ and $\sigma_{z}=0.16$.

Finally, we need to specify a number of institutional parameters. The marginal corporate tax rate, $\tau$ is set to $20 \%$ to reflect the effect of of individual taxes on distributions and interest on

\footnotetext{
${ }^{13}$ Early examples include Bansal and Yaron (2004) in models with exogenous quantities and Lochstoer and Kaltenbrunner (2009), Croce (2010) and Kung and Schmid (2015) in settings with production.
} 
the effective marginal tax rate. We choose the bankruptcy cost parameter, $\phi$ to generate average recoveries on defaulted bonds around $75 \%$ of face value (Warner (1977)). Formally, we set the value of $\phi$ so that in default:

$$
\frac{(1-\phi)(1-\delta+\exp (x+z))}{Q\left(s_{0}, b, z\right)}=0.75
$$

where $Q\left(s_{0}, b, z\right)$ is the value of debt (relative to $k$ ) initially raised by the firm on average.

Finally, we determine equity and bond issuance costs, $\kappa_{e}$ and $\kappa_{b}$ to be consistent with stylized facts about firms' issuing activity. Specifically, we set $\kappa_{e}$ to match the empirical frequency of equity issuances, while the $\kappa_{b}$ effectively pins down the average maturity of corporate bonds, which we take to be five years.

For the version with credit market specific shocks, we assume that recovery rates in bankruptcy fluctuate over time, as a result of exogenous shocks to liquidation values. In this case, we assume that $\phi$ can take two values: a benchmark value of 0.4 reflecting average bankruptcy costs and an extreme (but rare) value of 0.8 that occurs during crisis. We also assume that $\phi$ evolves over time according to a two-state Markov chain with the following transition probabilities:

$$
\begin{gathered}
P\left[\phi_{t+1}=0.4 \mid \phi_{t}=0.4\right]=0.98, \\
P\left[\phi_{t+1}=0.8 \mid \phi_{t}=0.8\right]=0.5,
\end{gathered}
$$

Thus periods of crisis are both rare and fairly temporary.

\section{Findings}

We begin describing our quantitative findings by summarizing the basic implications of our model for means and dynamics of major aggregate quantities and asset prices. We then examine the role of leverage and capital structure for these findings. Finally we discuss how the evolution of the cross-sectional distribution of firms over time becomes a determinant of economic cycles. In particular we illustrate how movements in the cross-section amplify aggregate fluctuations and how credit spreads emerge as an indicator and predictor informative about these movements. 
Most of our quantitative results are based on simulations. To construct the statistics reported below we solve the benchmark model and alternative specifications by numerical dynamic programming as detailed in Section 3. We then simulate the implied equilibrium policies at quarterly frequency to construct 1000 independent panels of 64 years each and report averages across all simulations. Unless otherwise noted we always report the relevant empirical moments for the sample period between 1951 and 2014.

\subsection{Basic Properties of the Benchmark Model}

Table 2 reports basic macroeconomic and financial moments from the benchmark model. We start by noting that the model is quantitatively consistent with salient features of US business cycles, as captured by the volatilities of consumption, output, and investment. Similarly, the share of investment (and hence consumption) is plausible and close to the actual data.

Moreover, both the level of the risk free rate and the equity premium are very close to those observed in the data, and this match does not require the very large movements in the risk free rate often associated with habit preferences. Essentially, this is because the persistent stochastic variation in growth rates generated by our model increases the household's precautionary savings thereby lowering equilibrium interest rates.

While Bansal and Yaron (2004) have shown that accounting for long run movements in consumption and dividends, combined with preferences for an early resolution of uncertainty, delivers realistic risk premia in an endowment economy setting, this has proved harder to implement in general equilibrium production economies (Kaltenbrunner and Lochstoer (2010), Campanale, Castro and Clementi (2009), Croce (2010)). This is because in a production economy, general equilibrium restrictions often tie dividends very closely to consumption, while empirically, dividends are much more volatile than consumption. In our setup, however, financial leverage (endogenously) breaks the tight link between dividends and consumption and renders dividends an order of magnitude more volatile. This allows us to generate a more realistic amount of stock market volatility and is crucial in matching the aggregate equity premium. ${ }^{14}$

\footnotetext{
${ }^{14}$ Although we do not report these numbers here, the model also generates a slow moving pattern in leverage (Lemmon, Roberts and Zender (2008)) and the long run movements in aggregate dividends observed in the data
} 
Table 2 also shows that our baseline calibration implies realistic levels of corporate leverage ratios, default rates and credit spreads (these statistics are based on the average properties of the cross-sectional distribution of firms). Plausibly low equilibrium leverage ratios reflect realistic pricing of corporate debt. As in recent work by Bhamra et al (2008) and Chen (2008), our success in matching credit market data relies on the the fact that default occurs in periods of very high marginal utility, thereby significantly increasing the effective cost of default and the required compensation to bondholders. In our model, however, cash flow and discount rates are jointly endogenously determined.

Tying macroeconomic fluctuations to variation in default rates is then the key component of the large credit spreads and the reason we can match the data along this dimension. Given our (realistic) default rate of $1.11 \%$, risk neutral valuation implies a credit spread of about 28 basis points. ${ }^{15}$ Instead, our calibration generates a credit spread of 108 basis points, much closer to the empirical counterpart. Unlike other popular macro models with credit markets, it is this credit risk premium, induced by the (endogenous) covariance between default rates and the market price of risk, and not default rates that account for the large credit spreads in our model. ${ }^{16}$

Lastly, Table 2 documents that our heterogeneous firm economy also generates realistic crosssectional dispersion in equity risk premia. More specifically, the model generates a spread between the returns on portfolios of the highest and the lowest decile of book-to-market sorted companies, that is, a value premium $E\left[r^{v}-r^{g}\right]$, in line with the empirical evidence. A quantitatively realistic value premium is broadly consistent with the literature modeling links between irreversible investment and asset returns (see e.g. Gomes et al (2003), Zhang (2005), Garleanu et al (2012)), much as we do. On the other hand, our approach differs from these models in that growth option exercise is linked to capital structure through debt financing. We explore the asset pricing implications of this added element of realism below.

(Bansal and Yaron (2004))

${ }^{15}$ Give our target recovery rate of about $75 \%$.

${ }^{16}$ Our decomposition is also consistent with Elton and Gruber (2001) who estimate that about two thirds of the credit spreads are due to the credit risk premium. 


\subsection{Cyclical Patterns and Return Predictability}

Risk premia on both stocks and corporate bonds reflect firms' performance and policies across economic cycles, induced by stochastic variation in growth rates. Table 3 documents the cyclical behavior of several investment and financing variables by reporting their cross-correlations with GDP. Although all variables have the correct cyclical behavior the implied correlations are sometimes higher than in the data. Intuitively this is because without financing shocks, this probably relies too much on a single source of aggregate uncertainty and innovations in output growth are too closely tied to those in aggregate productivity.

Persistence in productivity shocks implies a strongly pro-cyclical behavior in both aggregate investment and net entry as new firms enter the market and build up productive capacity in anticipation of higher future profits. As in the data, our firms are more likely to issue equity during good times in the model, although the correlation with economic activity is modest. This is because equity issues take place to both fund investment in good times and also to recapitalize the firm in bad times. Debt issues are also mildly procyclical, as in the data. A finding not reported in the table is the fact that the frequency of debt issuance is also procyclical, making effective debt maturity countercyclical. This is because firms are more likely to pay the transaction costs associated with refinancing in times of high profits.

Since market values of firms and price-dividend ratios are both strongly pro-cyclical, the model naturally generates a realistic countercyclical pattern in market leverage. ${ }^{17}$ Elevated leverage in downturns renders both default rates and credit spreads strongly countercyclical since default becomes less attractive when profits are temporarily high. This endogenous comovement underlies the substantial credit risk premium embedded in the pricing of corporate bonds.

In our general equilibrium economy, the cyclical behavior of firms' policies affects agents' consumption and thus marginal utilities through the stochastic discount factor. A convenient way to capture the persistent stochastic variation in agents' consumption growth is to estimate a process, in the spirit of Bansal and Yaron (2004), from simulations of our model. We compute expected

\footnotetext{
${ }^{17}$ The model is thus consistent with evidence that leverage is procyclical at refinancing points, while countercyclical in the cross-section, see e.g. Bhamra, Kuehn, and Strebulaev (2010), Danis, Rettl, and Whited (2014)
} 
consumption growth and the conditional volatility of realized consumption growth in the state space and use simulations to calculate the moments. An estimate for the dynamics of consumption growth in our baseline model is given by:

$$
\begin{aligned}
\mathrm{E} \Delta c_{t+1} & =0.00043+0.935 \mathrm{E} \Delta c_{t}+0.262 \sigma_{c t} \varepsilon_{t+1} \\
\sigma_{c, t+1}^{2} & =0.0081^{2}+0.971\left(\sigma_{c t}^{2}-0.0081^{2}\right)+0.249 \times 10^{-6} w_{t+1}
\end{aligned}
$$

where $\Delta c_{t+1}=\log C_{t+1} / C_{t}, \sigma_{c t}$ is the conditional volatility of $\Delta c_{t+1}$, and $\varepsilon_{t+1}$ and $w_{t+1}$ are i.i.d. shocks. While consumption is endogenous in our general equilibrium model, its growth rate exhibits both a fair amount of persistent long-run variation and endogenous time variation in its conditional volatility. ${ }^{18,19}$

This estimated consumption growth process reveals how the model generates endogenously conditional movements in risk that must be compensated in asset markets. Table 4 documents this by showing how popular indicators of equity and credit market conditions, such as valuation ratios and credit spreads, are informative about long-horizon stock market excess returns. As in the data, high price-dividend ratios predict lower expected stock returns going forward, while credit spreads forecast high average stock returns.

While some of the patterns regarding cross-sectional and time-series predictability in returns are reminiscent of the literature studying the links between growth options and returns (see e.g. Gomes et al (2003), Gala (2010), Garleanu, et al (2012)), our work is distinct by linking movements in quantities and risk premia to credit markets. We now examine the role of credit markets for our results more closely.

\footnotetext{
${ }^{18}$ To compare with Bansal and Yaron (2004), we time aggregate their model to a quarterly frequency, and obtain: $\mathrm{E} \Delta c_{t+1}=0.939 \mathrm{E} \Delta c_{t}+0.151 \sigma_{c t} \varepsilon_{t+1}$ and $\sigma_{c, t+1}^{2}=0.0022^{2}+0.962\left(\sigma_{c t}^{2}-0.0022^{2}\right)+8.282 \times 10^{-6} w_{t+1}$.

${ }^{19}$ Related papers that examine mechanisms that endogenously generate long-run movements in consumption growth include Kaltenbrunner and Lochstoer (2010), Kung and Schmid (2015), Collin Dufresne, Johannes and Lochstoer (2016), neither of which work through credit markets, as we do.
} 


\subsection{The Role of Leverage and Credit Risk}

\subsubsection{Aggregate Moments}

Table 5 provides insights into the role of leverage for aggregate fluctuations and risk premia by comparing the main macroeconomic and financial statistics for a variety of alternative model specifications.

First, and foremost, an all equity version of our economy does not generate enough volatility in equity returns and macro quantities and is also not capable of matching the observed equity premium. This model also produces an unrealistically high equilibrium risk free rate. Compared with this all equity economy, the unconditional volatility of consumption increases by about $35 \%$ in the baseline, levered, economy. Notably, the value premium implied by the all equity model, while still positive, is also substantially smaller. Intuitively, in our model, growth options are partially debt financed, so that value firms in the cross-section also exhibit higher leverage ratios. ${ }^{20}$ The cross-sectional differences in leverage between growth and value firms thus amplify the dispersion in equity risk. In the context of our model, this dispersion accounts for a substantial fraction of the observed value premium. ${ }^{21}$

To better understand this result, consider what happens when we simply lever up returns on growth and value portfolios, for the all equity economy, using the average leverage ratio for these firms in the baseline economy. Allowing for cross sectional variation in leverage, even if exogenous, doubles the value premium in the an equity model. The baseline model, with endogenous leverage adds two interacting forces that further amplify the value premium. First, the dispersion of leverage across growth and value portfolios is countercyclical. Second, in the absence of Modigliani-Miller, firms investment and financing choices affect aggregate consumption, so that episodes of widening cross-sectional dispersion endogenously coincide with an elevated market price of risk.

The column entitled "Lid Def." considers a version of the model where firms default on their debt obligations whenever their internal cash flows fall short of their debt obligations, that is, in

\footnotetext{
${ }^{20}$ The average leverage ratio in the baseline model is about0.55 for value firms and about 0.2 for growth firms. Ozdagli's (2012) reports similar estimates in the CRSP data.

${ }^{21}$ Alternatively, while a positive value premium is consistent with models with irreversibilities in investment and operating leverage (Gomes et al (2003), Zhang (2005), Carlson et al (2006), Garleanu et al (2012)), our findings can be seen instead as ascribing a relevant component of the value premium to financial leverage.
} 
case of a "liquidity" default. Formally, the default cut-off (6) now obeys:

$$
\exp (x+\bar{z})-\delta=b
$$

Now firms are prevented from covering liquidity shortfalls by contracting additional capital in equity and debt markets. As the table shows, this form of default has a slightly dampening effect on aggregate volatility. Intuitively, firms anticipate they will default earlier and more often, so they will take slightly less debt. Notably, however although default rates in this case are substantially higher, we see only a modest increase in average credit spreads. This is because default boundaries now tied to profitability not equity values, are far less sensitive to cyclical movements in the aggregate economy.

Finally, we also consider the case with credit shocks, in the form of variation in the recovery parameter $\phi$. Table 5 shows that the unconditional moments are essentially unchanged from the baseline specification. However, the presence of credit shocks significantly alters cyclical patterns in firms' financing and investment policies documented in Table 6. These cyclical patterns now become much more realistic. This is because credit shocks immediately impact both leverage and spreads while spreading to GDP growth more slowly, through changes in consumption and investment over time.

\subsubsection{Leverage and Return Predictability}

Tables 7 and 8 offer an in depth examination of the role of leverage in generating the patterns in time-varying expected stock returns documented above.

The easiest way to do this is by looking at the implications of an all equity model. In this case valuation ratios are still able to predict future equity returns, but the effects are substantially muted. To better understand this result it is useful to re-estimate the dynamics of consumption growth for the all equity version of the model, which yields:

$$
\begin{aligned}
\mathrm{E} \Delta c_{t+1} & =0.00076+0.814 \mathrm{E} \Delta c_{t}+0.212 \sigma_{c, t} \varepsilon_{t+1} \\
\sigma_{c, t+1}^{2} & =0.0063^{2}+0.906\left(\sigma_{c, t}^{2}-0.0063^{2}\right)+0.097 \times 10^{-6} w_{t+1}
\end{aligned}
$$


Comparing with the benchmark model we see that now consumption growth exhibits less persistent long-run movements, while variation in volatility is both smaller and less persistent.

"Levering up" the equity returns exogenously by assuming firms have a constant leverage ratio, which is here set to the average for the baseline model as before, has almost no impact on the predictability regressions as Table 7 shows. Another useful thought-experiment is to instead "lever up" the returns from an all equity model, by using an exogenous leverage process that has both the same mean and the same cyclical correlation of leverage in the baseline model. Table 7 shows how this exogenously countercyclical leverage enhances return predictability. This occurs because in our consumption-based asset pricing model realistic leverage dynamics amplify conditional movements in consumption betas. Our model thus suggests that empirically a considerable fraction of the movements in expected stock returns can be simply ascribed to realistically countercyclical leverage dynamics.

The baseline model further departs from this setting because the Modigliani-Miller theorem does not apply, so that leverage and asset risks are jointly determined. Inspection of Table 7 shows that this joint interaction further exacerbates return predictability. Intuitively, absent ModiglianiMiller, firms' financial decisions affect equilibrium consumption. In particular, long-term debt propagates the persistence of the consumption process, while procyclical refinancing further amplifies its stochastic variation. ${ }^{22}$ Allowing for credit shocks has only a relatively minor impact on the ability of price-dividend ratios to predict stock returns.

However, as Table 8 shows, credit shocks do increase the ability of credit spreads to forecast future stock returns. This occurs because now credit spreads encode additional information about credit market conditions affecting firms investment and financing decisions, which are reflected in stock returns going forward.

\subsection{The Cross-Section of Leverage and Default Risk}

All moments documented so far have been obtained by aggregating across the cross-sectional distribution of firms in our model. We now examine the properties and determinants of the firm

\footnotetext{
${ }^{22}$ Firms are less likely to pay the transaction costs associated with debt restructuring in low productivity times, raising effective average debt maturity and further depressing investment via debt overhang.
} 
distribution. As before we report quantitative results both for our baseline parameter choices and for a few alternative specifications to illustrate some of the mechanisms behind our findings. We also document how cross-sectional variation in firm characteristics is important for time series movements in the aggregate economy.

Table 9 reports a first set of results. Panel A documents properties of firm-level investment and financing policies along with their cross-sectional dispersion. The benchmark model is generally consistent with basic facts about corporate policies. Notably, the model reproduces the lumpy nature of firms' investment and financing behavior quite accurately. Firms' investment comes in rare but sizable spikes, as does equity issuance. Assuming liquidity default produces only a slight reduction in the amount of cross-sectional dispersion in our model, while adding credit shocks has no discernible impact on these properties.

Panel B shows that the cross-sectional dispersion of firm characteristics also exhibits some distinct cyclical patterns. While the cross-sectional dispersion of market leverage and credit spreads widens in downturns, differences in firms' investment opportunities are mildly exacerbated in expansions. As shown in Table 3 above, debt issuance is procyclical since firms are less likely to pay the transaction costs associated with debt restructuring in downturns. This makes effective debt maturity countercyclical, and implies that firms tend to be further away from the optimal capital structure, thereby widening the dispersion in leverage and credit spreads. In other words, the tail of the distribution of firms burdened with high leverage widens in recessions, rendering them more sensitive to additional disturbances.

Finally, Table 10 compares the model's predictions to core conditional moments of the crosssectional distribution of firm level leverage identified in the empirical capital structure literature. These are based in empirical regressions relating relating corporate leverage to several financial indicators (e.g. Rajan and Zingales (1995)). This table shows that our model reproduces the observed negative relationships between leverage and both profitability and Tobin's Q. With persistent shocks, both highly profitable and high Q firms have large investment opportunities going forward. Because equity issuances are costly, such firms will borrow more prudently to avoid floatation costs. The table also shows the model produces a strong positive relation between firm size and leverage. 


\subsection{Other Parameter Choices}

Table 11 examines the sensitivity of some of the main moments to some key model parameters. The table shows that when shocks to the stochastic growth rate are not sufficiently persistent, so that $\rho_{x}$ is lower, the model fails to generate enough volatility in equity returns and thus cannot match the observed equity premium. In this case the model also produces an unrealistically high equilibrium risk free rate. Similarly, lowering the persistence, $\rho_{x}$, reduces default rates and credit spreads. Clearly, firms find it easier to avoid default when temporary bad times are expected to be shorter. In turn, equilibrium leverage ratios are higher than in the baseline case. Persistence has profound effects on the asset pricing implications of our model but does not significantly alter the level or volatility of the main macro quantities, at least not at these relatively short horizons.

Removing either equity issuance or debt issuance costs provides firms with additional financial flexibility to cover cash shortfalls by issuing new equity or to refinance more cheaply. Not surprisingly, this tends to dampen aggregate volatility slightly and produce a corresponding reduction in aggregate risk premia. Eliminating issuance costs also produces a small increase in average leverage.

\section{Business Cycles}

The previous section documented how credit markets have significant effects on aggregate and cross-sectional volatility and risk in our model. We now explore some of the macroeconomic effects of this friction and show how it produces both an endogenous amplification of shocks and, perhaps more significantly, it endows credit spreads with the power to predict future movements in output and investment.

\subsection{Amplification of Business Cycles}

Figure 4 looks at the impact of fluctuations in credit markets on key macroeconomic quantities. It directly compares the response to exogenous technology shocks in our benchmark economy with levered firms to the response in an all equity model. Output and investment growth all respond by between $35 \%$ to $50 \%$ more to an increase in the level of aggregate productivity. Thus leverage 
introduces a powerful amplification mechanism because positive productivity shocks also reduce the probability of default and thus lower the effective cost of new debt. This raises ex-ante firm value and encourages firm creation and investment spending. ${ }^{23}$ These amplifications results are only a little stronger than those in Bernanke et al (1999). This is expected since both models are calibrated to similar investment to output ratios and average credit spreads. The key difference is that our transmission mechanism relies on movements in the credit risk premium, instead of unobserved default rates, to produce realistic variations in credit spreads and the cost of capital.

\subsection{Predicting Business Cycles}

We now investigate the ability of credit spreads to forecast movements in the aggregate economy in our model. ${ }^{24}$ Table 12 shows the results of regressing one year ahead growth in (log) output and investment, respectively, on the average (value-weighted) credit spread at time $t$. The table shows that elevated credit spreads forecast future declines in aggregate output and investment in ways that are statistically and economically meaningful. The estimated coefficients are similar in magnitude to those found in our empirical counterparts.

Within the context of our model, we also present additional results that shed new light on the economic mechanism underlying the predictive power of credit spreads. The table shows that this predictability survives even after we control for the current state of aggregate productivity, $x_{t}$. Recall that in the baseline model without credit shocks aggregate variables such as output and investment, depend only on the two-dimensional aggregate state $s=(x, \mu(\cdot))$. Thus, unlike standard aggregate models there is here an important role for firm heterogeneity which is captured, to some extent, by variation in credit spreads. Intuitively, credit spreads contain information about firms in the tail of the distribution which are burdened by elevated leverage, those that are most likely to be plagued by debt overhang and imminent default.

We can also decompose the credit spread in two components, a risk neutral spread, that captures expectations of losses over a given horizon, and the credit risk premium, which accounts for the

\footnotetext{
${ }^{23}$ Because we abstract from variations in labor supply these results are probably a lower bound on the amount of endogenous propagation that this mechanism can generate.

${ }^{24}$ E.g. Gilchrist et al (2008), Lettau and Ludvigson (2004) and Mueller (2008).
} 
covariation of these losses with agents' marginal utility. Table 12 shows that in our model the risk neutral credit spread component does not significantly forecast future movements in either output or investment, confirming the crucial role that risk premia plays in our model.

The lower panel of Table 12 recalculates these predictability regressions for the augmented version of our model with credit shocks. Formally, with credit shocks, the aggregate state space becomes $s=(x, \phi, \mu)$ and credit spreads now capture at least some of the variation in the last two. The results show how in this case credit spreads become somewhat more important in this world, especially regarding future investment.

\section{Conclusion}

This paper studies a general equilibrium model with heterogeneous firms making optimal investment and financing decisions under uncertainty, and brings together many core insights from asset pricing, capital structure, and macroeconomics. The model reconciles, in a unified framework, several core stylized facts about asset returns and many key features in macroeconomic aggregate and firm-level investment and financing variables. Specifically, we show that our model produces a sizable average equity premium and credit spread, together with plausibly low average returns on safe assets. It also implies that, in the time series, both price-dividend ratios and credit spreads have substantial predictive power for future stock returns, while generating a significant value premium in the crosssection of stock returns. A major contribution of our model is that it delivers an explicit connection between fluctuations in the cross-sectional distribution of firms and the time-series movements in macroeconomic aggregates and financial prices.

In the model, quantitatively realistic asset return dynamics are driven by empirically plausible, endogenous movements in leverage, both in time series and cross-section. Endogenous movements in leverage and risk premia contribute to the amplification and propagation of aggregate consumption risks and volatility. This raises the volatility of the market price of risk and produces quantitatively realistic risk premia. Importantly, endogenous default also increases the volatility of consumption during recessions, as the mass of firms burdened by excessive leverage and closer to default grows. As a consequence, the equilibrium market price of risk also becomes sharply countercyclical. Coun- 
tercyclical leverage drives up risk premia on financial assets in downturns which, in the time series, is naturally reflected in both price-dividend ratios and credit spreads. As a consequence, expected returns on stocks and bonds are higher in recessions, raising the cost of capital and lowering investment and output growth. Cross-sectionally, because investment is, at least partially, debt financed, value firms tend to have higher leverage ratios and these cross-sectional differences in leverage between growth and value firms amplify the dispersion in equity risk, and are a major driver of the value premium.

Endogenous movements in credit markets thus allow our model to match the observed conditional and unconditional movements in both financial prices and macroeconomic quantities in a parsimonious setting. 


\section{References}

Ai, Hengjie, Max Croce, and Kai Li, 2013, Toward a Quantitative General Equilibrium Asset Pricing Model with Intangible Capital, Review of Financial Studies 62, 491-530

Bansal, Ravi and Amir Yaron, 2004, Risks for the Long Run: A Potential Resolution of Asset Pricing Puzzles, Journal of Finance 59, 1639-1672

Begenau, Juliane and Juliana Salomao, 2015, Firm Financing over the Business Cycle, working paper, Harvard University

Belo, Frederico, Pierre Collin Dufresne and Robert Goldstein, 2014, Dividend Dynamics and the Term Structure of Dividend Strips, Journal of Finance, 70, 1115-1160

Bhamra, Harjoat, Lars-Alexander Kühn and Ilya Strebulaev, 2010, The Levered Equity Risk Premium and Credit Spreads: A Unified Framework, Review of Financial Studies 23, 645703

Bhamra, Harjoat, Lars-Alexander Kühn and Ilya Strebulaev, 2010, The Aggregate Dynamics of Capital Structure and Macroeconomic Risk, Review of Financial Studies 23, 4187-4241

Bernanke, Ben, Mark Gertler, and Simon Gilchrist, 1999, The Financial Accelerator in a Quantitative Business Cycle Framework, in Handbook of Macroeconomics, Edited by Michael Woodford and John Taylor, North Holland.

Chang, Ganlin and Suresh Sundaresan, 2005, Asset Prices and Default-Free Term Structure in an Equilibrium Model of Default, Journal of Business, 78, 1215-1266

Chen, Long, Pierre Collin-Dufresne and Robert Goldstein, 2009, On the Relation between Credit Spread Puzzles and the Equity Premium Puzzle, Review of Financial Studies 22, 3367-3409

Chen, Hui, 2010, Macroeconomic Conditions and the Puzzles of Credit Spreads and Capital Structure, Journal of Finance 65, 2171-2212 
Collin Dufresne, Pierre, Michael Johannes and Lars Lochstoer, 2016, Parameter Learning in General Equilibrium: The Asset Pricing Implications, American Economic Review, 106, 664-698

Covas, Francisco and Wouter Den Haan, 2011, The Role of Debt and Equity over the Business Cycle, American Economic Review 101, 877-899

Croce, Massimiliano, 2014, Long-Run Productivity Risk: A New Hope For Production-Based Asset Pricing?, Journal of Monetary Economics 66, 13-31

Danis, Andras, Daniel Rettl, and Toni Whited, 2014, Refinancing, Profitability, and Capital Structure, Journal of Financial Economics, 114 , 424-443

Davis, Steven and John Haltiwanger, 1992, Gross Job Creation, Gross Job Destruction, and Employment Reallocation, Quarterly Journal of Economics, 107, 19-63

Drechsler, Itamar and Amir Yaron, 2011, What's Vol Got To Do With It , Review of Financial Studies, 24, 1-45

Eisfeldt, Andrea and Adriano Rampini, 2006, Capital reallocation and liquidity, Journal of Monetary Economics 53369399

Elton, Edwin and Martin Gruber, 2001, Explaining the Rate Spread on Corporate Bonds, Journal of Finance 56, 247-277

Fama, Eugene F., and Kenneth R. French, 1992, Business Conditions and Expected Returns on Stocks and Bonds, Journal of Financial Economics, 25, 23-49.

Fama, Eugene F., and Kenneth R. French, 1993, Common Risk Factors in the Returns on Stocks and Bonds, Journal of Financial Economics, 33, 3-56.

Fama, Eugene F., and Kenneth R. French, 1996, Multifactor Explanations of Asset Pricing Anomalies, Journal of Finance, 51, 55-84.

Favilukis, Jack, Xiaoji Lin, and Xiaofei Zhao, 2015, The Elephant in the Room: The Impact of Labor Obligations on Credit Risk, working paper, University of British Columbia 
Gala, Vito, 2010, Investment and Returns, working paper, London Business School

Garleanu, Nicolae, Stavros Panageas, and Jianfeng Yu, 2012, Technological Growth and Asset Prices, Journal of Finance, 67, 1265-1292

Gertler, Mark and Peter Karadi, 2011, A Model of Unconventional Monetary Policy, Journal of Monetary Economics 58, 17-34

Gilchrist, Simon,Jae Sim and Egon Zakrajsek, 2014, Uncertainty, Financial Frictions and Investment Dynamics, working paper, Boston University

Gilchrist, Simon and Egon Zakrajsek, 2012, Credit Spreads and Business Cycle Fluctuations, American Economic Review 102, 1692-1720

Gomes, João F., 2001, Financing Investment, American Economic Review, 90, 5, 1263-1285.

Gomes, João F., Urban Jermann and Lukas Schmid, 2015, Sticky Leverage, working paper, University of Pennsylvania

Gomes, João F., Leonid Kogan, and Lu Zhang, 2003, Equilibrium Cross-Section of Returns, Journal of Political Economy, 111, 693-731.

Gomes, João F., Amir Yaron, and Lu Zhang, 2006, Asset Pricing Implications of Firm's Financing Constraints, Review of Financial Studies, 19, 1321-1356.

Gomes, João F., and Lukas Schmid, 2010, Levered Returns, Journal of Finance 65, 467-494

Gourio, Francois, 2013, Credit Risk and Disaster Risk, American Economic Journal: Macroeconomics $5,1-34$

Hackbarth, Dirk, Jianjun Miao and Erwan Morellec, 2006, Capital Structure, Credit Risk and Macroeconomic Conditions, Journal of Financial Economics, 82, 519-550

Hennessy, Christopher, and Amnon Levy, 2007, Why does Capital Structure Choice Vary with Macroeconomic Conditions? , Journal of Monetary Economics, 54, 1545-1564 
Hennessy, Christopher, and Toni Whited, 2005, Debt Dynamics Journal of Finance, 60, 1129-1165

Jermann, Urban, 1998, Asset Pricing in Production Economies, Journal of Monetary Economics $41,257-275$

Jermann, Urban and Vincenzo Quadrini, 2012, Macroeconomic Effects of Financial Shocks, American Economic Review 102, 238-71

Jermann, Urban and Vivien Yue, 2007, Interest Rate Swaps and Corporate Default, working paper, University of Pennsylvania.

Kaltenbrunner, Georg and Lars Lochstoer, 2010, Long Run Risk through Consumption Smoothing, Review of Financial Studies 23, 3141 - 3189

Kiyotaki, Nobu and John Moore, 1997, Credit Cycles, Journal of Political Economy, 105, 211-248

Keim, Donald and Robert Stambaugh, 1986, Predicting Returns in the Stock and Bond Markets, Journal of Financial Economics, 17, 357-390

Khan, Aubhik, and Julia Thomas, 2013, Credit Shocks and Aggregate Fluctuations in an Economy with Production Heterogeneity, Journal of Political Economy, 121, pages 1055 - 1107

Kogan, Leonid and Dimitris Papanikolaou, 2014, Growth Opportunities, Technology Shocks, and Asset Prices, Journal of Finance, 69, 675-718.

Krusell, Per and Anthony Smith, 1998, Income and Wealth Heterogeneity in the Macroeconomy, Journal of Political Economy, 106, 867-896

Kuehn, Lars-Alexander and Lukas Schmid, 2014, Investment-based Corporate Bond Pricing, Journal of Finance 69, 27412776

Kung, Howard and Lukas Schmid, 2015, Innovation, Growth and Asset Prices, Journal of Finance 70,10011037

Leland, Hayne, 1994, Corporate Debt Value, Bond Covenants, and Optimal Capital Structure, Journal of Finance, 49, 1213-1252 
Lemmon, Michael, Michael Roberts and Jaime Zender, Back to the Beginning: Persistence and the Cross-Section of Corporate Capital Structure, Journal of Finance, 63, 1575 - 1608

Lettau, Martin and Sydney Ludvigson, 2002, Time-Varying Risk Premia and the Cost of Capital: An Alternative Implication of the Q-Theory of Investment, Journal of Monetary Economics, $49,31-66$

Livdan, Dmitry, Horacio Sapriza and Lu Zhang, 2009, Financially constrained stock returns, Journal of Finance 64, 1827-1862

Miao, Jianjun and Pengfei Wang, Credit Risk and Business Cycles, working paper, Boston University, 2010.

Mitra, Indrajit, 2015, Aggregate Dynamics in an Economy with Optimal Long-term Financing, working paper, University of Michigan

Müller, Philippe, 2008, Credit Spreads and Real Activity, working paper, London School of Economics

Obreja, Iulian, 2013, Book-to-Market Equity, Financial Leverage, and Cross-Section of Stock Returns, Review of Financial Studies, 26, 1146-1189

Ozdagli, Ali, 2012, Financial Leverage, Corporate Investment and Stock Returns, Review of Financial Studies, 25, 1033-1069

Papanikolaou, Dimitris, 2011, Investment Shocks and Asset Prices, Journal of Political Economy, $119,639-685$

Philippon, Thomas, 2009, The Bond Market's Q, Quarterly Journal of Economics 124, 1011-1056

Rajan, Raghuram and Luigi Zingales, 1995, What Do We Know about Capital Structure? Some Evidence From International Data, Journal of Finance, 50,1421-1460

Stock, James and Mark Watson, 1999, Business Cycle Fluctuations in U.S. Macroeconomic Time Series, Handbook of Macroeconomics 
Strebulaev, Ilya, 2007, Do Tests of Capital Structure mean what they say?,Journal of Finance, $62,1747-1788$

Sundaresan, Suresh, and Neng Wang, 2014, Dynamic Investment, Capital Structure, and Debt Overhang, Review of Corporate Finance Studies, 1-42

Tallarini, Thomas, 2000, Risk-sensitive Real Business Cycles, Journal of Monetary Economics 45, 507532

Zhang, Lu, 2005, The Value Premium, Journal of Finance 60, 67-103 


\section{Appendix: Properties of the Firm's Problem}

This appendix establishes some of the basic properties of main value functions used to describe the problem of equity and bondholders. In all cases we assume that the economy is in steady-state so the cross section distribution $\mu$ is constant over time.

Lemma 1. the market value of debt, $Q(\cdot)$, is increasing in $x$, $z$ and $\phi$

Proof Monotonicity in $x$ follows from the facts that $\bar{z}(\cdot)$ is decreasing (see below) and the recovery payment increasing in $x$. Monotonicity in $z$ follows from the persistence in (3) and the fact that the recovery payment also increasing in $z^{\prime}$. Monotonicity in $\phi$ follows from the fact that the recovery payment increasing in $\phi$.

Lemma 2. The normalized equity value $P(\cdot)$, is increasing in $z$ and $x$, and declining in leverage $b$;

Proof This follows directly from the fact that equity cash flows, $\pi(\cdot)$, net of investment spending, $i$, are increasing in $z$ and $x$ while declining in $b$.

Monotonicity of the value function ensures the existence of a (unique) default threshold. In addition to these properties, we can show that limited liability which endows equity with an exit option and increases the value of uncertainty, implies that $P(\cdot)$ will be convex in $\exp (z)$.

Lemma 3. The default cutoff, $\bar{z}(\cdot)$, is increasing in the coupon $b$ and declining in $x$

Proof This follows from the fact that $P(\cdot)$ is declining in $b$ and increasing in $x$. $\square$

Lemma 4. The investment cutoff, $\bar{i}(\cdot)$, is increasing in $z$ and $x$ and (weakly) decreasing in the existing coupon payment $b$. The optimal debt policy $\bar{b}(\cdot)$ is increasing in $z$.

Proof The monotonicity of the policy functions in $z$ and $x$ follows directly from Lemmas 1 and 2. In addition, higher $b$ might trigger the equity issuance indicator $\chi_{e}>0$ to switch from 0 to 1 , reducing $\bar{i}(\cdot)$ implied by $(11)$. 


\section{Appendix: Computational Details}

Computation of the competitive equilibrium is complicated by the endogeneity of the pricing kernel, which embodies the equilibrium market clearing conditions through its dependence on aggregate consumption and wealth. The main difficulty here that these quantities are jointly determined with the cross-sectional distribution, $\mu$, a high-dimensional object.

Our solution algorithm exploits the parsimonious characterization of the distribution $\mu$ and relies on three basic techniques. First, in our model both consumption and wealth are endogenously growing. To obtain a stationary representation of these quantities, we divide them by the aggregate capital stock $K$, which shares the same endogenous stochastic trend. Accordingly, we define $\hat{c} \equiv \frac{C}{K}$ and $\hat{w} \equiv \frac{W}{K}$. Second, we re-normalize the value functions for debt and equity to express them in units of marginal utility which is computationally more convenient. Third, following Krusell and Smith (1998), the cross-sectional distribution $\mu$ is approximated by a low-dimensional state variable that summarizes the relevant information in $\mu$.

The expression for the pricing kernel (23) guides both our choice of the approximate state space and the re-normalizations. To that end, we define the function:

$$
p(\hat{c}, \hat{w})=\hat{c}^{-\frac{\kappa}{\sigma}} \hat{w}^{\kappa-1}
$$

Next, for any generic financial claim $V$ in our model, we define $\hat{V}(s, z, b)=V(s, z, b) p(\hat{c}, \hat{w})$, which allows us to rewrite the corresponding recursions in a computationally more convenient form ${ }^{25}$.

For simplicity, we illustrate the procedure using the inaction value of equity, $P^{0}(b, z, s)$, using the representation

$$
\hat{P}^{0}(s, z, b) \equiv P^{0}(s, z, b) p(\hat{c}, \hat{w})
$$

The other relevant normalized value functions $\hat{P}^{I}, \hat{P}$, and $\hat{Q}$ are defined accordingly. Our numerical strategy is based on numerically iterating on these value functions to obtain individual policy

\footnotetext{
${ }^{25}$ Note that any $V$ is normalized by construction, as it is expressed in per unit of capital terms
} 
functions and then aggregate. The value function for $\hat{P}^{0}$ satisfies:

$$
\begin{aligned}
\hat{P^{0}}(s, z, b)= & \max \left\{0, \max _{b^{\prime}}\left\{\chi_{e}\left(1+\kappa_{e}\right) \pi\left(b, b^{\prime}, z, s\right) p(\hat{c}, \hat{w})\right.\right. \\
& \left.\left.+E \beta^{\kappa}\left(\frac{\hat{c}\left(s^{\prime}\right)+\hat{w}\left(s^{\prime}\right)}{\hat{w}\left(s^{\prime}\right)}\right)\left(\frac{K\left(s^{\prime}\right)}{K(s)}\right)^{\zeta} \int_{\bar{z}\left(b^{\prime}, s^{\prime}\right)} \hat{P}\left(b^{\prime}, z^{\prime}, s^{\prime}\right) N\left(d z^{\prime} \mid z\right)\right\}\right\},
\end{aligned}
$$

where $s=(x, \mu)$ denotes the aggregate state and the term $\left(\frac{K^{\prime}}{K}\right)^{\zeta}$ with $\zeta=-\kappa / \sigma-\kappa-1$ comes from the detrending procedure. Clearly, the value function depends on the cross-sectional distribution as $\hat{c}, \hat{w}$ and $K$ do.

In the spirit of Krusell and Smith (1998), we choose a low-dimensional approximation of the high-dimensional state space by means of variables that capture the relevant information embedded in $\mu$ well. Similar to Krusell and Smith' approach, most of the current literature uses the aggregate capital stock $K$ as a sufficient state variable. In our setup, where tails of the firm distribution carry important information about pricing, this is insufficient. Rather, we choose to approximate the state space by means of the current aggregate shock $x$ and current consumption (relative to trend) $\hat{c}$, so that we set $\hat{s} \equiv(x, \hat{c})$. Using $\hat{c}$ as a state variable is natural in a model with heterogeneous firms as consumption reflects output and corporate policies of the entire firm distribution.

In order to solve for the functions, we need to forecast future consumption, wealth and the future capital stock, given current state variables. Again following Krusell and Smith (1998) we parameterize both the law of motion for aggregate consumption $\hat{c}^{\prime}$ and the growth rate of the capital stock as log linear functions of the aggregate state, $x$ and $\hat{c}$ :

$$
\begin{aligned}
\log \hat{c}^{\prime} & =\alpha_{0}+\alpha_{1} \log x+\alpha_{2} \log \hat{c} \\
\log \left(\frac{K^{\prime}}{K}\right) & =\eta_{0}+\eta_{1} \log x+\eta_{2} \log \hat{c}
\end{aligned}
$$

for some coefficient vectors $\alpha$ and $\eta$. Finally, it is straightforward to determine wealth using the no-arbitrage condition $W(s)=C(s)+E M\left(s, s^{\prime}\right) W\left(s^{\prime}\right)$, whose detrended version,

$$
\hat{w}=\hat{c}+E \beta^{\kappa}\left(\frac{\hat{c}^{\prime}}{\hat{c}}\right)^{-\frac{\kappa}{\sigma}}\left(\frac{\hat{w}^{\prime}+\hat{c}^{\prime}}{\hat{w}}\right)^{\kappa-1}\left(\frac{K^{\prime}}{K}\right)^{\kappa\left(1-\frac{1}{\sigma}\right)} \hat{w}^{\prime}
$$


can be determined efficiently using value function iteration, given the forecasting rules above for $\hat{c}^{\prime}$ and $\frac{K^{\prime}}{K}$.

With these rules at hand we compute firm value and policies. Note that we need to solve for the value functions simultaneously, as equity values and bond prices are jointly determined with default boundaries. These are then aggregated and checked for consistency using the general equilibrium condition (26).

More precisely, we use the following iterating procedure:

- Discretize the state space by choosing discrete grids for $b$ and $\hat{c}$, and the shocks $x$ and $z^{26},{ }^{27}$.

- Guess initial vectors $\alpha^{0}$ and $\eta^{0}$

- Iterate on the functional equations for $\hat{P}^{0}, \hat{P}^{I}, \hat{P}$, and $\hat{Q}$ and compute decision rules for investment, default and leverage.

- Simulate decisions rules and compute the implied equilibrium allocations for $C$ and $W$. We obtain the equilibrium time series for $C$ by clearing the market each period using a bisection method.

- Use implied time series for $x, K$ and $\hat{c}$ to revise $\log$ linear rules for $\hat{c}^{\prime}$ and $\frac{K^{\prime}}{K}$ and check fit.

- Iterate until convergence.

All of our forecasting regressions have $R^{2}$ s above 0.99 , and adding additional state variables (such as the cross-sectional standard deviation of capital or coupon payments) do not change the results. As an additonal accuracy test, we check that the implied wealth, computed as the aggregate equity and bond values plus tax proceeds, coincides with the aggregate wealth as obtained from the no-arbitrage recursion.

\footnotetext{
${ }^{26}$ As $b$ is a function of both $x$ and consumption $\hat{c}$, so $n b=n x \times n c$, where $n_{i}$ is the number of points in the grid for $i=b, z, x, \hat{c}$.

${ }^{27}$ We use the procedure in Rouwenhorst (1995) since are highly persistent.
} 
Table 1: Quarterly Calibration

\begin{tabular}{llc}
\hline Parameter & Description & Model \\
\hline A. Preferences & & \\
$\beta$ & & 0.994 \\
$\psi$ & Subjective discount factor & 2 \\
$\gamma$ & Elasticity of intertemporal substitution & 10 \\
B. Technology & Risk aversion & \\
$g$ & Size of growth options & 1.16 \\
$\alpha$ & Relative size of entrants & 0.2 \\
$\delta$ & Maintenance investment rate & 0.021 \\
$\rho_{x}$ & Persistence of aggregate shock & 0.96 \\
$\sigma_{x}$ & Volatility of aggregate shock & 0.012 \\
$\rho_{z}$ & Persistence of idiosyncratic shock & 0.92 \\
$\sigma_{z}$ & Volatility of idiosyncratic shock & 0.16 \\
& & \\
C. Institutions & & 0.2 \\
$\tau$ & Effective corporate tax rate & 0.41 \\
$\phi$ & Bankruptcy cost & 0.035 \\
$\kappa_{e}$ & Equity issuance cost & 0.022 \\
$\kappa_{b}$ & Bond issuance cost & \\
& &
\end{tabular}

This table reports the basic parameter choices for our model and their associated empirical targets. These choices are discussed in detail in subsection 3.2. The model is calibrated at quarterly frequency. 
Table 2: Aggregate Moments: Benchmark

\begin{tabular}{lcc}
\hline & Data & Model \\
\hline & & \\
A. Macro Moments & & \\
$\sigma[\Delta c]$ & 1.68 & 1.71 \\
$\frac{\sigma[\Delta c]}{\sigma[\Delta y]}$ & 0.7 & 0.66 \\
$\frac{\sigma[\Delta i]}{\sigma[\Delta y]}$ & 4.59 & 4.17 \\
$\frac{I}{Y}$ & 0.19 & 0.22 \\
& & \\
B. Asset Pricing Moments & & \\
$E\left[r^{f}\right]$ & 1.69 & 1.25 \\
$\sigma\left[r^{f}\right]$ & 2.21 & 1.26 \\
$E\left[r^{e}-r^{f}\right]$ & 4.29 & 4.46 \\
$\sigma\left[r^{e}\right]$ & 17.79 & 13.55 \\
& & \\
C. Cross Sectional Moments & & \\
Default rate, $D$ & $1.48 \%$ & $1.11 \%$ \\
Credit spread, CS & $0.95 \%$ & $1.08 \%$ \\
Market leverage & 0.35 & 0.37 \\
$E\left[r^{v}-r^{g}\right]$ & 4.12 & 4.24 \\
& & \\
\hline
\end{tabular}

This table reports unconditional sample moments generated from the simulated data of our benchmark model. The model's moments come from averages across 1000 simulations of 64 years each. The empirical sample comes from the BEA and CRSP. In the table $\Delta w$ denotes the $\log$ difference in the variable $W$. The return on equity, $r^{e}$ refers to the value weighted aggregate stock market return, while the risk free rate $r^{f}$ denotes the return on a one year government bond. The credit spread is the spread between AAA-rated and BAA-rated bonds. The spread $E\left[r^{v}-r^{g}\right]$ captures the return difference between the highest and lowest quintiles of book-to-market portfolios. All returns are adjusted for annual CPI inflation. The default rate is from Moody's. The parameter values used in the benchmark simulation are reported in Table 1. All data are annualized. 
Table 3: Financing Over Business Cycle: Benchmark

\begin{tabular}{lcc}
\hline Correlation with $\Delta y$ & Data & Model \\
\hline & & \\
Investment growth, $\Delta i$ & 0.81 & 0.76 \\
Net entry & 0.44 & 0.91 \\
Market leverage & -0.11 & -0.53 \\
Price-Dividend ratio, $P D$ & 0.42 & 0.74 \\
Debt issuance & 0.33 & 0.45 \\
Equity issuance & 0.10 & 0.27 \\
Default rate, $D$ & -0.33 & -0.83 \\
Credit spread, $C S$ & -0.36 & -0.68 \\
& & \\
\hline
\end{tabular}

This table reports the correlation of key macro and financial variables with changes in log GDP, $\Delta y$ in the data and in our benchmark model. The model's moments come from averages across 1000 simulations of 64 years each. The empirical sample comes from the BEA, CRSP, Moody's and the Board of Governors of the Federal Reserve. The parameter values used in the benchmark simulation are reported in Table 1. All data are annualized. 
Table 4: Return Predictability: Benchmark

\begin{tabular}{|c|c|c|c|c|c|c|}
\hline \multirow[t]{2}{*}{ Predictor } & & \multicolumn{5}{|c|}{ Horizon (in years) } \\
\hline & & 1 & 2 & 3 & 4 & 5 \\
\hline \multirow[t]{8}{*}{ A. $\log P D$} & \multicolumn{6}{|c|}{ Data } \\
\hline & \multirow[t]{2}{*}{$\beta_{n}$} & -0.132 & -0.231 & -0.292 & -0.340 & -0.430 \\
\hline & & $(-3.219)$ & $(-2.962)$ & $(-2.949)$ & $(-3.036)$ & $(-3.185)$ \\
\hline & $\mathrm{R}^{2}$ & 0.090 & 0.157 & 0.193 & 0.214 & 0.254 \\
\hline & \multicolumn{3}{|c|}{ Benchmark Model } & & & \\
\hline & $\beta_{n}$ & -0.084 & -0.141 & -0.195 & -0.251 & -0.314 \\
\hline & & $(-2.81)$ & $(-3.07)$ & $(-3.18)$ & $(-3.34)$ & $(-3.48)$ \\
\hline & $\mathrm{R}^{2}$ & 0.047 & 0.092 & 0.135 & 0.181 & 0.226 \\
\hline \multirow[t]{8}{*}{ B. $C S$} & \multicolumn{3}{|c|}{ Data } & & & \\
\hline & \multirow[t]{2}{*}{$\beta_{n}$} & 3.293 & 1.758 & 1.326 & 2.102 & 2.755 \\
\hline & & $(4.30)$ & $(2.97)$ & $(2.49)$ & $(4.04)$ & $(5.22)$ \\
\hline & $\mathrm{R}^{2}$ & 0.039 & 0.018 & 0.017 & 0.034 & 0.048 \\
\hline & \multicolumn{3}{|c|}{ Benchmark Model } & & & \\
\hline & \multirow[t]{2}{*}{$\beta_{n}$} & 1.925 & 2.134 & 2.388 & 2.602 & 2.861 \\
\hline & & $(2.636)$ & $(2.787)$ & $(2.920)$ & $(3.085)$ & $(3.221)$ \\
\hline & $\mathrm{R}^{2}$ & 0.032 & 0.061 & 0.090 & 0.116 & 0.132 \\
\hline
\end{tabular}

This table reports excess stock return, $r_{t, t+n}^{e}-r_{t, t+n}^{f}$ forecasts for horizons, $n$, between one and five years in both the data and in our benchmark model. Simulated moments come from averages across 1000 simulations of 64 years each. The empirical sample comes from the CRSP. The parameter values used in the benchmark simulation are reported in Table 1. Excess stock return forecasts using both the log-price-dividend ratio: $r_{t, t+n}^{e}-r_{t, t+n}^{f}=$ $\alpha_{n}+\beta_{n} \log \left(P_{t} / D_{t}\right)+\epsilon_{t+1}\left(\right.$ panel A), and the value-weighted credit spread: $r_{t, t+n}^{e}-r_{t, t+n}^{f}=\alpha_{n}+\beta_{n} \mathrm{CS}_{t}+\epsilon_{t+1}$ (panel B). T-statistics are reported in parentheses. All standard errors are corrected with Newey-West. 
Table 5: Aggregate Moments: Role of Leverage

Data Benchmark All Equity Exog. Lev Liq. Def. $\quad$ Credit Shocks

A. Macro Moments

$\sigma[\Delta c]$
$\frac{\sigma[\Delta c]}{\sigma[\Delta y]}$
$\frac{\sigma[\Delta i]}{\sigma[\Delta y]}$
$\frac{I}{Y}$

1.68 1.71 1.23

0.7

0.66

0.66

1.23

1.48

1.79

4.59

4.17

3.90

0.62

0.65

0.70

0.19

0.22

0.20

3.90

4.03

4.31

0.20

0.20

0.22

B. Asset Pricing Moments

$E\left[r^{f}\right]$

$\sigma\left[r^{f}\right]$

1.69

1.25

1.26

1.96

1.96

1.52

1.04

1.15

$E\left[r^{e}-r^{f}\right]$

4.29

4.46

1.04

2.59

3.77

5.11

9.17

10.23

1.23

13.55

$1.11 \%$

$0.00 \%$

$0.00 \%$

$2.83 \%$

$0.00 \%$

$0.00 \%$

$1.65 \%$

$0.95 \%$

0.37

0.00

0.37

0.32

$1.16 \%$

0.35

4.24

0.86

1.93

3.45

0.35

$E\left[r^{v}-r^{g}\right]$

4.12

.

\begin{abstract}
This table reports unconditional sample moments generated from the simulated data of our benchmark model. The model's moments come from averages across 1000 simulations of 64 years each. The empirical sample comes from the BEA and CRSP. In the table $\Delta w$ denotes the log difference in the variable $W$. The return on equity, $r^{e}$ refers to the value weighted aggregate stock market return, while the risk free rate $r^{f}$ denotes the return on a one year government bond. The credit spread is the spread between AAA-rated and BAA-rated bonds. The spread $E\left[r^{v}-r^{g}\right]$ captures the return difference between the highest and lowest quintiles of book-to-market portfolios. All returns are adjusted for annual CPI inflation. The default rate is from Moody's. The parameter values used in the benchmark simulation are reported in Table 1. Firms in the all equity model have no leverage. Results for the exogenous leverage model are constructed by simply "levering up" returns in the all equity model with a market leverage ratio of 0.37 . The liquidity default model modifies the default decision of the firm to $\exp (x+\bar{z}(b, x))-\delta<b$. Finally, the credit shocks model assumes the recovery rate on debt is stochastic and follows the Markov process in (29). All data are annualized.
\end{abstract}


Table 6: Business Cycle Properties

\begin{tabular}{lccccc}
\hline Correlation with $\Delta y$ & Data & Benchmark & All Equity & Liquid. Default & Credit Shock \\
\hline & & & & & \\
Investment growth, $\Delta i$ & 0.81 & 0.76 & 0.72 & 0.70 & 0.55 \\
Net entry & 0.44 & 0.91 & 0.85 & 0.88 & 0.68 \\
Market leverage & -0.11 & -0.53 & 0.00 & -0.41 & -0.34 \\
Price-Dividend ratio, $P D$ & 0.42 & 0.74 & 0.68 & 0.69 & 0.58 \\
Debt issuance & 0.33 & 0.45 & 0.00 & 0.38 & 0.38 \\
Equity issuance & 0.10 & 0.27 & 0.13 & 0.00 & 0.07 \\
Default rate, $D$ & -0.33 & -0.83 & 0.00 & -0.52 & -0.42 \\
Credit spread, $C S$ & -0.36 & -0.68 & 0.00 & -0.44 & -0.37 \\
& & & & & \\
\hline
\end{tabular}

This table reports the correlation of key macro and financial variables with changes in log GDP, $\Delta y$ in the data and in our benchmark model. The model's moments come from averages across 1000 simulations of 64 years each. The empirical sample comes from the BEA, CRSP, Moody's and the Board of Governors of the Federal Reserve. The parameter values used in the benchmark simulation are reported in Table 1. Firms in the all equity model have no leverage. The liquidity default model modifies the default decision of the firm to $\exp (x+\bar{z}(b, x))-\delta<b$. Finally, the credit shocks model assumes the recovery rate on debt is stochastic and follows the Markov process in (29). All data are annualized. 
Table 7: Stock Return Predictability with PD ratios

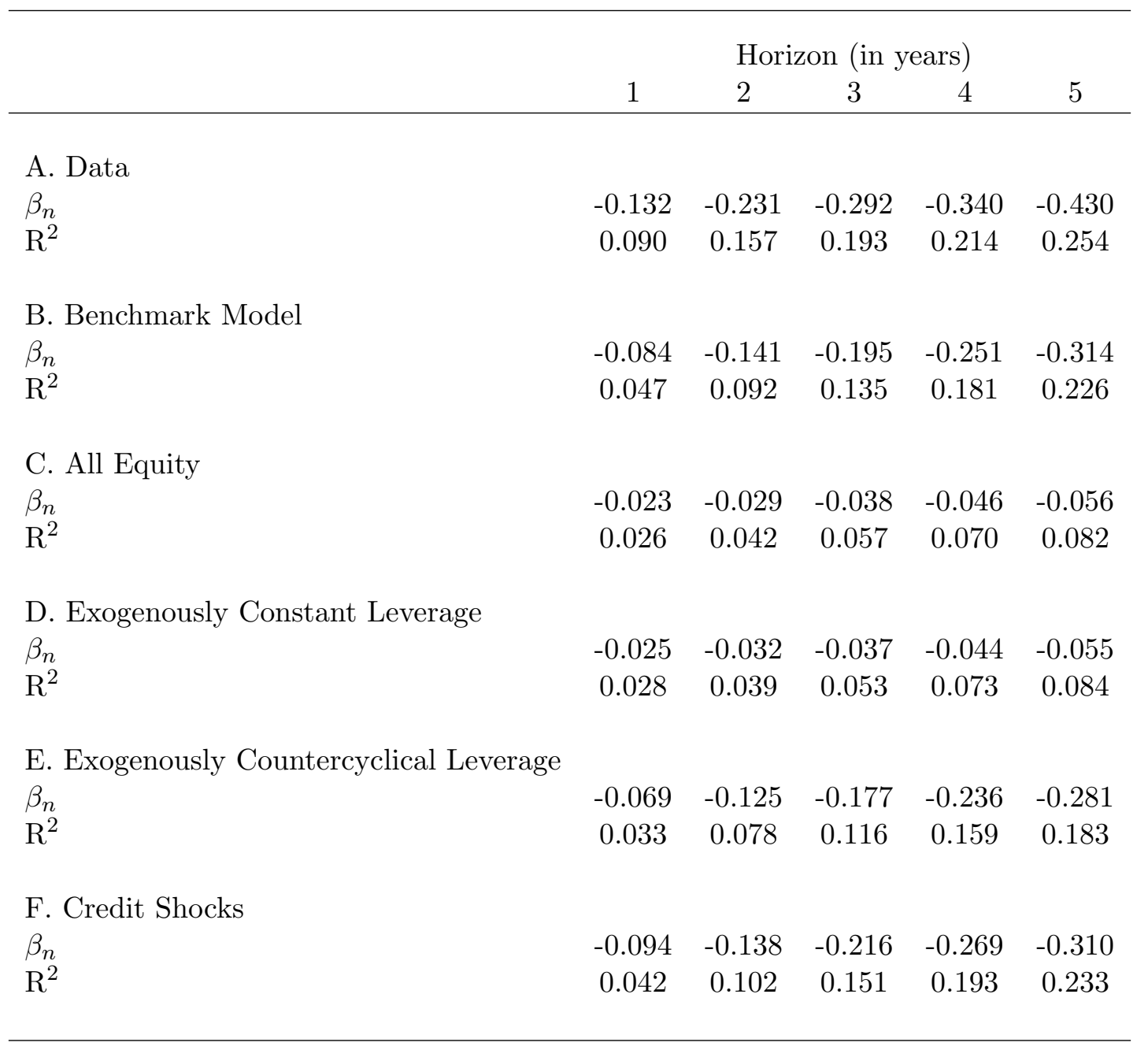

This table reports excess stock return, $r_{t, t+n}^{e}-r_{t, t+n}^{f}$ forecasts for horizons, $n$, between one and five years in both the data and in our benchmark model. We report population estimates. The empirical sample comes from the CRSP. The parameter values used in the benchmark simulation are reported in Table 1 . In panel D equity returns are levered exogenously by a constant market leverage ratio of 0.37 . Panel E refers to a specification with exogenous market leverage with a mean of 0.37 and correlation with log changes in GDP, $\Delta y$, of -0.53 . Excess stock return forecasts using both the log-price-dividend ratio: $r_{t, t+n}^{e}-r_{t, t+n}^{f}=\alpha_{n}+\beta_{n} \log \left(P_{t} / D_{t}\right)+\epsilon_{t+1}$ (panel A), and the value-weighted credit spread: $r_{t, t+n}^{e}-r_{t, t+n}^{f}=\alpha_{n}+\beta_{n} \mathrm{CS}_{t}+\epsilon_{t+1}$ (panel B). 
Table 8: Stock Return Predictability with Credit Spreads

\begin{tabular}{lccccc}
\hline & \multicolumn{5}{c}{ Horizon (in years) } \\
& 1 & 2 & 3 & 4 & 5 \\
\hline & & & & & \\
A. Data & & & & & \\
$\beta_{n}$ & 3.293 & 1.758 & 1.326 & 2.102 & 2.755 \\
$\mathrm{R}^{2}$ & 0.039 & 0.018 & 0.017 & 0.034 & 0.048 \\
& & & & & \\
B. Benchmark Model & & & & & \\
$\beta_{n}$ & 1.925 & 2.134 & 2.388 & 2.602 & 2.861 \\
$\mathrm{R}^{2}$ & 0.036 & 0.061 & 0.090 & 0.116 & 0.132 \\
& & & & & \\
$\mathrm{C}$. Credit Shocks & & & & & \\
$\beta_{n}$ & 2.344 & 2.761 & 2.943 & 3.126 & 3.455 \\
$\mathrm{R}^{2}$ & 0.050 & 0.077 & 0.106 & 0.151 & 0.164 \\
& & & & & \\
\hline
\end{tabular}

This table reports excess stock return, $r_{t, t+n}^{e}-r_{t, t+n}^{f}$ forecasts for horizons, $n$, between one and five years in both the data and in our benchmark model. We report population estimates. The empirical sample comes from the CRSP. The parameter values used in the benchmark simulation are reported in Table 1. Panel C reports the results for a model where the recovery rate on assets upon default is stochastic and follows the Markov process (29). Excess stock return forecasts using both the log-price-dividend ratio: $r_{t, t+n}^{e}-r_{t, t+n}^{f}=\alpha_{n}+\beta_{n} \log \left(P_{t} / D_{t}\right)+\epsilon_{t+1}$ (panel A), and the value-weighted credit spread: $r_{t, t+n}^{e}-r_{t, t+n}^{f}=\alpha_{n}+\beta_{n} \mathrm{CS}_{t}+\epsilon_{t+1}$ (panel B). 
Table 9: Cross-sectional Moments

Data Benchmark All Equity Liquid. Default Credit Shocks

$\begin{array}{lccccc}\text { A. Moments } & & & & & \\ \text { Investment rate } & 0.03 & 0.03 & 0.02 & 0.03 & 0.03 \\ \text { Investment frequency } & 0.06 & 0.06 & 0.04 & 0.05 & 0.06 \\ \text { Tobin's Q } & 1.41 & 1.49 & 1.06 & 1.38 & 1.43 \\ \text { Frequency of equity issuance } & 0.08 & 0.07 & 0.19 & 0.06 & 0.09 \\ \text { Dispersion of market leverage } & 0.19 & 0.22 & 0.20 & 0.20 & 0.22 \\ \text { Dispersion of Q } & 0.62 & 0.28 & 0.18 & 0.24 & 0.30 \\ \text { Dispersion of credit spreads } & 0.41 \% & 0.37 \% & 0.00 \% & 0.30 \% & 0.41 \% \\ & & & & & -0.82 \\ \text { B. Correlations with } \Delta Y & & & & -0.61 & 0.09 \\ \text { Dispersion of market leverage } & -0.21 & -0.84 & 0.00 & 0.14 & -0.89 \\ \text { Dispersion of Q } & 0.06 & 0.17 & 0.10 & -0.66 & \end{array}$

This table reports average cross-sectional moments of firm characteristics across model specifications. The parameter values used in the benchmark simulation are reported in Table 1 . The liquidity default model modifies the default decision of the firm to $\exp (x+\bar{z}(b, x))-\delta<b$. Finally, the credit shocks model assumes the recovery rate on debt is stochastic and follows the Markov process in (29). The data are from the quarterly CRSP-Compustat file covering the years 1984 to 2014, except for the investment frequency that comes from Davis and Haltiwanger (1992). All moments are reported at quarterly frequency. 
Table 10: Cross-sectional Leverage Regressions

\begin{tabular}{lccc}
\hline & Data & Benchmark & Credit Shocks \\
\hline \multirow{2}{*}{ Size, $\log k$} & 0.009 & 0.028 & 0.016 \\
& $(10.65)$ & $(3.56)$ & $(3.24)$ \\
Market-to-book, $Q$ & -0.076 & -0.116 & -0.095 \\
& $(-40.42)$ & $(-2.83)$ & $(2.66)$ \\
Profitability & -0.286 & -0.441 & -0.517 \\
& $(-15.42)$ & $(-2.93)$ & $(-3.12)$ \\
\hline
\end{tabular}

This table reports cross-sectional Fama-Macbeth leverage regressions

$$
\text { Book Leverage }=\alpha_{0}+\alpha_{1} \log k+\alpha_{2} Q+\alpha_{3} \text { Profitability }
$$

in the data and across model specifications. The parameter values used in the benchmark simulation are reported in Table 1. The credit shocks model assumes the recovery rate on debt is stochastic and follows the Markov process in (29). Size is the value of Plant Property and Equipment, Market-to-book equals Tobin's Q, and profitability is the ratio of profits to size. The data are from the quarterly CRSP-Compustat file covering the years 1984 to 2014 . All moments are reported at quarterly frequency. 
Table 11: Aggregate Moments: Robustness

\begin{tabular}{lccccc}
\hline & Data & Benchmark & $\rho_{x}=0.9$ & $\kappa_{e}=0$ & $\kappa_{b}=0$ \\
\hline & & & & & \\
A. Macro Moments & & & & & \\
$\sigma[\Delta c]$ & 1.68 & 1.71 & 1.55 & 1.61 & 1.58 \\
$\frac{\sigma[\Delta c]}{\sigma[\Delta y]}$ & 0.7 & 0.66 & 0.67 & 0.63 & 0.61 \\
$\frac{\sigma[\Delta i]}{\sigma[\Delta y]}$ & 4.59 & 4.17 & 3.85 & 4.08 & 3.96 \\
$\frac{I}{Y}$ & 0.19 & 0.22 & 0.21 & 0.21 & 0.21 \\
B. Asset Pricing Moments & & & & & \\
$E\left[r^{f}\right]$ & 1.69 & 1.25 & 3.37 & 1.31 & 1.26 \\
$\sigma\left[r^{f}\right]$ & 2.21 & 1.26 & 1.09 & 1.18 & 1.11 \\
$E\left[r^{e}-r^{f}\right]$ & 4.29 & 4.46 & 1.53 & 3.53 & 3.29 \\
$\sigma\left[r^{e}\right]$ & 17.79 & 13.55 & 6.13 & 12.24 & 11.84 \\
& & & & & \\
C. Cross Sectional Moments & & & & & \\
Default rate & $1.48 \%$ & $1.11 \%$ & $0.56 \%$ & $0.85 \%$ & $1.02 \%$ \\
Credit spread & $0.95 \%$ & $1.08 \%$ & $0.48 \%$ & $0.79 \%$ & $0.96 \%$ \\
Market leverage & 0.35 & 0.37 & 0.43 & 0.40 & 0.38 \\
$E\left[r^{v}-r^{g}\right]$ & 4.12 & 4.24 & 1.33 & 2.85 & 2.32 \\
& & & & & \\
\hline
\end{tabular}

This table reports unconditional sample moments generated from the simulated data of some key variables of our model under different parameter specifications. We report averages across 1000 simulations of 64 years. All data are annualized. The return on equity refers to the value weighted aggregate stock market return. The parameter values used in the benchmark simulation are reported in table 1. Data counterparts come from the BEA and CRSP . 


\section{Table 12: Forecasting with Credit Spreads}

\begin{tabular}{|c|c|c|c|c|c|c|c|}
\hline & \multicolumn{3}{|c|}{$\Delta y_{t, t+4}$} & \multicolumn{4}{|c|}{$\Delta i_{t, t+4}$} \\
\hline & Data & & 3enchmark & Data & & Benchmark & \\
\hline$C S_{t}$ & $\begin{array}{l}-3.89 \\
(-2.82)\end{array}$ & $\begin{array}{c}-2.49 \\
(-2.67)\end{array}$ & $\begin{array}{c}-1.18 \\
(-2.31)\end{array}$ & $\begin{array}{l}-9.71 \\
(-2.39)\end{array}$ & $\begin{array}{c}-7.16 \\
(-3.35)\end{array}$ & $\begin{array}{l}-3.05 \\
(-2.60)\end{array}$ & \\
\hline$x_{t}$ & & & $\begin{array}{c}2.58 \\
(3.08)\end{array}$ & & & $\begin{array}{c}4.73 \\
(2.94)\end{array}$ & \\
\hline$C S_{t}^{R N}$ & & & & & & & $\begin{array}{l}-1.81 \\
(-1.44)\end{array}$ \\
\hline & Data & & edit Shock & Data & & edit Shock & \\
\hline$C S_{t}$ & $\begin{array}{l}-3.89 \\
(-2.82)\end{array}$ & $\begin{array}{c}-1.96 \\
(-2.43)\end{array}$ & $\begin{array}{l}-1.13 \\
(-2.58)\end{array}$ & $\begin{array}{c}-9.71 \\
(-2.39)\end{array}$ & $\begin{array}{c}-9.15 \\
(-3.60)\end{array}$ & $\begin{array}{l}-4.27 \\
(-2.69)\end{array}$ & \\
\hline$x_{t}$ & & & $\begin{array}{c}2.25 \\
(2.82)\end{array}$ & & & $\begin{array}{c}3.91 \\
(2.45)\end{array}$ & \\
\hline$C S_{t}^{R N}$ & & & & & & & $\begin{array}{l}-2.10 \\
(-1.53)\end{array}$ \\
\hline
\end{tabular}

This table reports forecasting regressions for output and investment growth in both model specifications and the data. We regress 4-period ahead $\log$ growth in output and investment, respectively: $\Delta y_{t, t+4}=\log Y_{t+4} / \log Y_{t}$ and $\Delta i_{t, t+4}=\log I_{t+4} / \log I_{t}$ on the value weighted aggregate credit spread $C S_{t}$ at time t, and additional control variables. The risk-neutral credit spread $C S_{t}^{R N}$ is spread on bonds valued using the risk-neutral measure. T-statistics are reported in parentheses below. Statistics for the model are obtained by averaging the results from simulating the economy 1000 times over 64 years. Standard errors are corrected using Newey-West. 

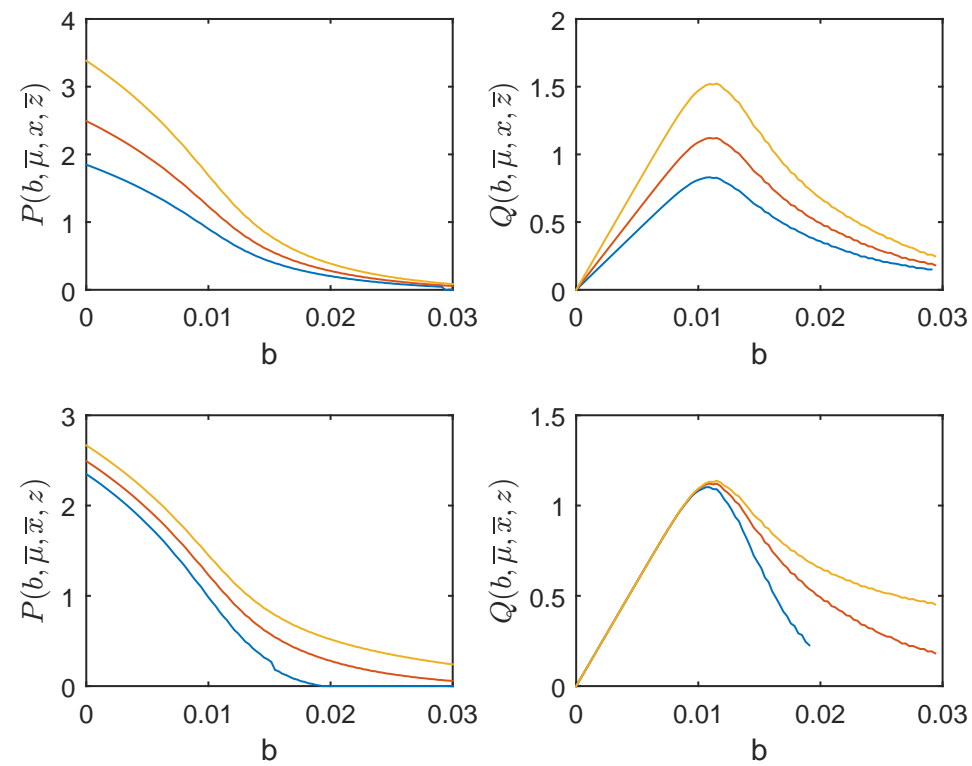

Figure 1: Equity and Debt Values. This figure plots the equity and debt value functions, $P(b, z, s)$ and $Q(b, z, s)$, respectively for our baseline calibration. The top panels shows the impact of a one standard deviation increase in aggregate productivity, $x$ while the bottom panels show the effects of a one-standard deviation increase in $z$. 

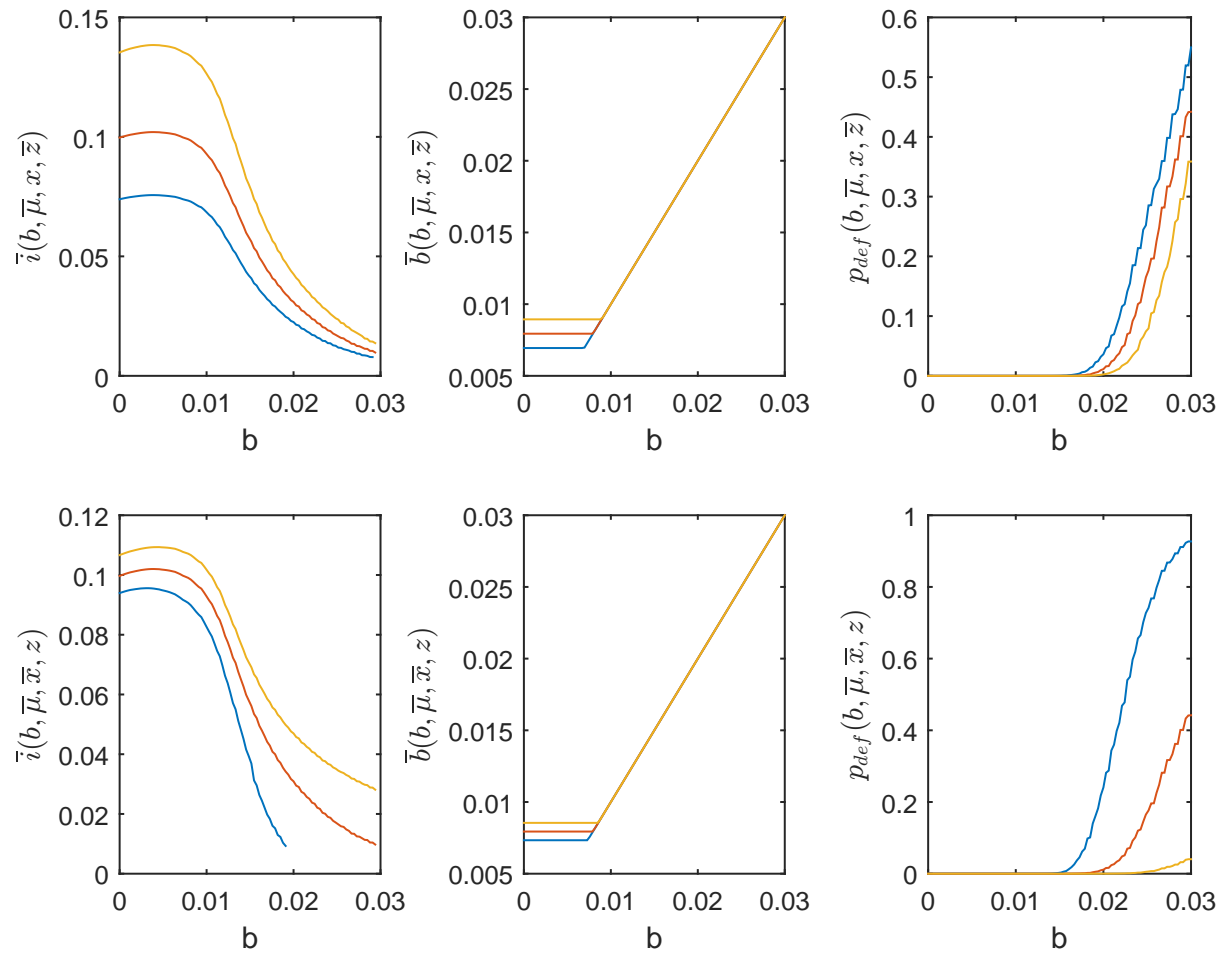

55

Figure 2: Optimal Policy Functions. This figure plots the policy functions for investment, $\bar{i}(b, z, s)$, debt $b^{\prime}(b, z, s)$ and default, $\bar{z}(b, s)$, for our baseline calibration. The top panels shows the impact of a one standard deviation increase in aggregate productivity, $x$ while the bottom panels show the effects of a one-standard deviation increase in $z$. 


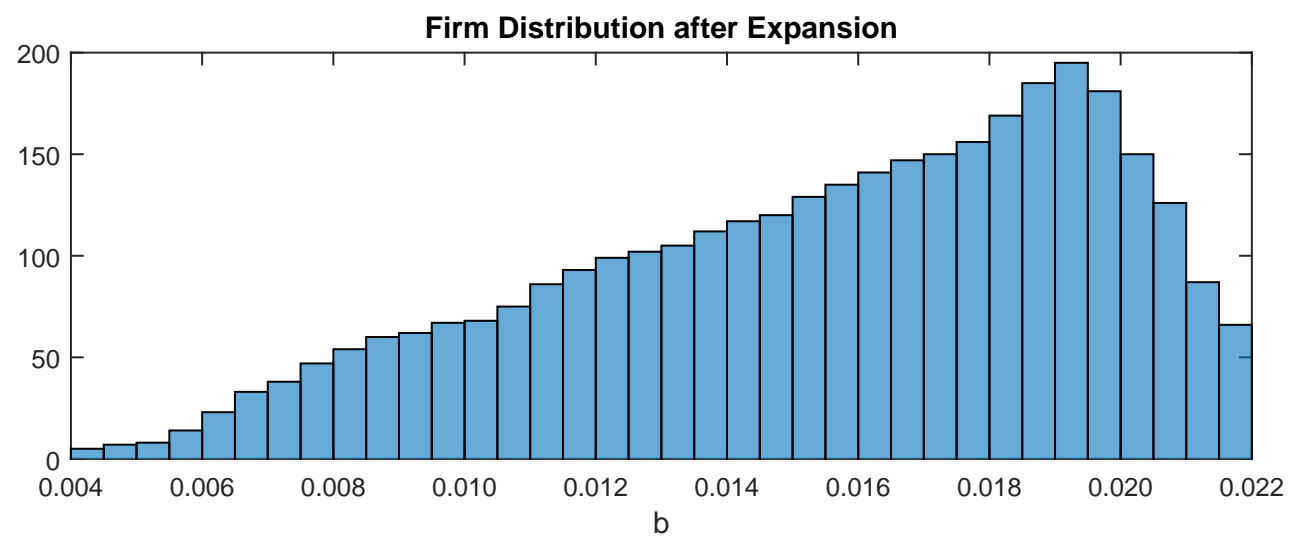

Firm Distribution after Contraction

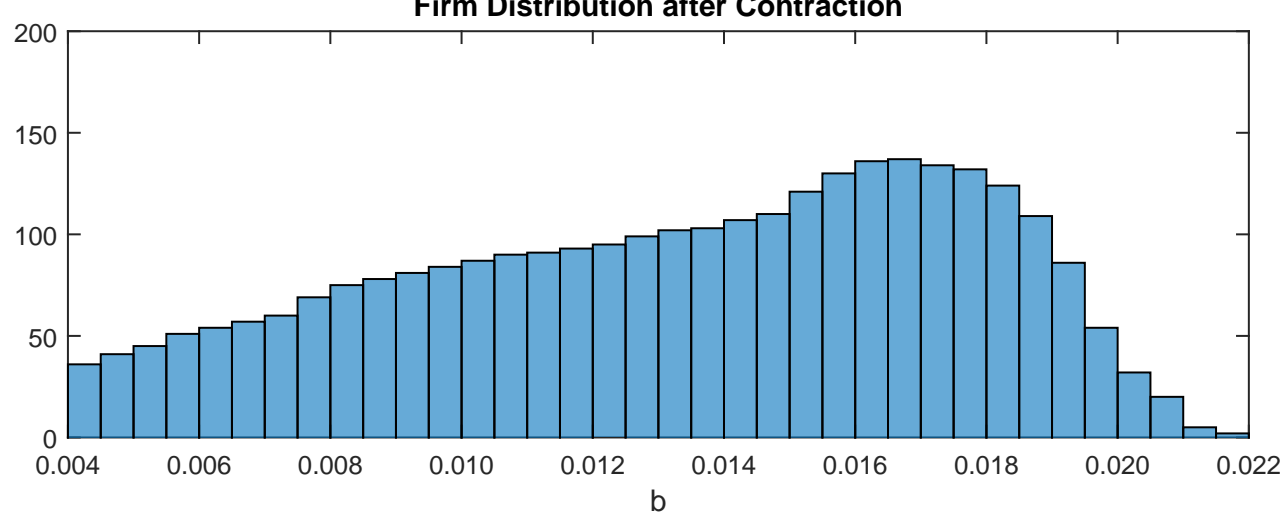

Figure 3: Cross-Sectional Distribution of Firms. This figure depicts the equilibrium cross-sectional distribution of firms, $\mu(s, b, z)$ for our baseline model. The top panel shows the impact of a one standard deviation increase in aggregate productivity, $x$ on $\mu(\cdot)$ while the bottom panel shows the effects of a one-standard deviation decrease in $x$. 

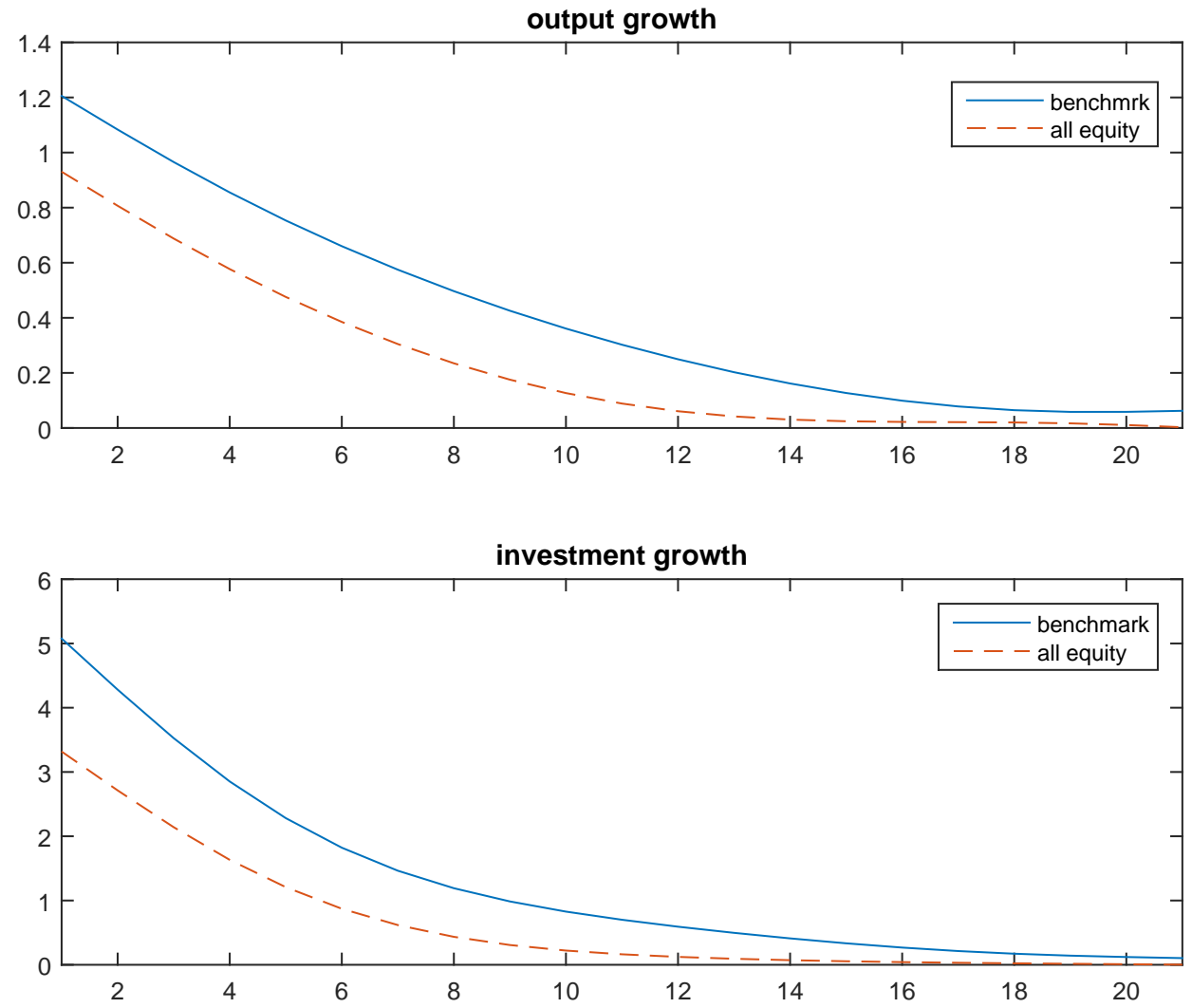

Figure 4: Business Cycle Amplification. This figure shows the response of output, consumption and investment growth to a one standard deviation positive innovation in aggregate technology in both our baseline levered economy and an alternative scenario where all investment is financed with equity alone. 